University of Navarra

\title{
HERB BEHAVIOR TOWARDS THE MARKET INDEX: EVIDENCE FROM 21 FINANCIAL MARKETS
}

\author{
Daxue Wang
}




\title{
HERB BEHAVIOR TOWARDS THE MARKET INDEX: EVIDENCE FROM 21 FINANCIAL MARKETS
}

\author{
Daxue Wang ${ }^{1}$
}

\begin{abstract}
This paper uses the cross-sectional variance of the betas to study herd behavior towards market index in major developed and emerging financial markets (categorized as developed group, Asian group, and Latin American group). We propose a robust regression technique to calculate the betas of the CAPM and those of the Fama-French three-factor model, with the intention of diminishing the impact of multivariate outliers in return data. Through the estimated values obtained from a state space model, we examine the evolution of herding measures, especially their pattern around sudden events such as the 1997-1998 financial crisis. This 1997-1998 turmoil turns out to have marked a turning point for most of the financial markets. We document a higher level of herding in emerging markets than in developed markets. We also find that the correlation of herding between two markets from the same group is higher than that between two markets from different groups. This paper will shed light on the calculation of beta and on the financial policy to understand the dynamics of herding in financial markets.
\end{abstract}

Classification JEL: CI, C60, G12, G14, G15

Keywords: Beta, Herding, Kalman Filter, Outlier, Robust Regression, Cycle.

${ }^{1} \mathrm{PhD}$ in Finance at IESE 


\section{HERB BEHAVIOR TOWARDS THE MARKET INDEX: EVIDENCE FROM 21 FINANCIAL MARKETS}

\section{Introduction}

In the financial literature, the behavior of an investor to imitate the observed actions of others or the movements of market, instead of following his own beliefs and information, is usually termed as "herding". Possibly herding is among the most mentioned but least understood terms in the financial lexicon. Difficulties in measuring and quantifying the existence of the behavior are obstacles to extensive research. Even so, there are at least two points people tend to unanimously agree upon. First, as one of the founding pillars in newly developed behavioral asset pricing area, herding helps to explain market-wide anomalies. Since individual biases are not influential enough to change market prices and returns, they have a real anomalous effect only if there is a social contamination with a strong emotional content, leading to more widespread phenomena such as herding. Second, it is generally accepted that the flood of herding may lead to a situation in which the market price fails to reflect all relevant information, and thus the market becomes unstable and moves towards inefficiency. Policy makers often express concerns that herding by financial market participants destabilizes markets and increases the fragility of the financial system. As a result, it is in their interest to curtail herding (Bikhchandani and Sharma, 2001).

Theoretical and empirical research on herding has been conducted in an isolated manner. Theoretical study focuses on the causes and implications of herding. The main consensus is that herding can be construed as being either a rational or irrational form of investor behavior. According to Devenow and Welch (1996), the irrational view focuses on investor psychology where an investor follows others blindly. On the other hand, imperfect information, concerns for reputation, and compensation structures foster rational herd behavior. ${ }^{1}$

The empirical studies thus far do not test a particular model of herding behavior described in the theoretical literature; instead, they gauge whether clustering of decisions, in a purely statistical sense, is taking place in financial markets or within certain investor groups. Two streams of empirical literature have been developed to investigate the existence of herding in

\footnotetext{
${ }^{1}$ See Bikhchandani and Sharma (2001) for an overview of the theoretical research on rational herd behavior in financial markets.
} 
financial markets. The first stream analyzes the tendency of individuals or certain groups of investors, such as mutual fund managers and financial analysts, to follow each other and trade an asset at the same time. In this case, detailed records of investors' trading activities are required. For instance, Lakonishok et al. (1992) measure herding as the average tendency of a group of money managers to buy or sell particular stocks at the same time, relative to what could be expected if the managers made their decision independently; Grinblatt et al. (1995) use data on portfolio changes of mutual funds between 1974 and 1984 to examine herding among fund managers and the relation of such behavior to momentum investment strategy; Wermers (1995) proposes a portfolio-change measure of herding, as the extent to which portfolio weights assigned to the various stocks by different money managers move in the same direction.

The second stream focuses on market-wide herding; that is, the collective behavior of all participants towards the market views and therefore buying or selling a particular asset at the same time. Christie and Huang (1995) regress the cross-sectional (market-wide) standard deviation of individual security returns on a constant and two dummy variables designed to capture extreme positive and negative market returns. They argue that, during periods of market stress, rational asset pricing would imply positive coefficients on these dummy variables, while herding would suggest negative coefficients. However, the introduction of dummy variables is entirely arbitrary, since the choice of what is meant by "extreme" is subjective. And they do not control for movements in fundamentals, so that it is hard to tell whether the negative coefficient, if there is any, is herding or just a sign that independent adjustment to fundamentals is taking place.

Based on the cross-sectional dispersion concept of Christie-Huang, Hwang and Salmon (2004) use the cross-sectional dispersion of beta to detect herding towards the market index. The authors apply their model to the United States and Korean stock markets, finding significant and persistent herd behavior over the sample period. One merit of their paper is that they separate the herding from the "spurious herding", i.e., from common movements in asset returns being induced by movements in fundamentals. Herding potentially leads to market inefficiency, whereas "spurious herding", or fundamental adjustment, reflects just an efficient reallocation of assets on the basis of common information on fundamentals. However, they derive the monthly beta of an asset with daily return data over a 1-month interval, a period that is too short to diminish the influence of unusual bad or good events of the company on the beta. ${ }^{2}$

The main purpose of our paper is to improve the Hwang-Salmon model and to investigate the herding towards the market in major financial markets. ${ }^{3}$ We do this in two dimensions. Firstly, it is not realistic to assume, as Hwang-Salmon do, that the log of cross-sectional standard deviation of betas is normally distributed with a static mean. Starting from the assumptions of the stock returns, we explore the distribution of the cross-sectional variance of betas. By doing this, we get a time-varying distribution of the cross-sectional dispersion of betas, which we believe is more realistic than the static one.

Secondly, we then apply the model to various financial markets, thereby obtaining the monthly herding measures in each market, through which we can work on our concept of relative herd

\footnotetext{
${ }^{2}$ Regarding the time period for which beta should be estimated, five years is a widely accepted alternative. With very short periods of time, there is the risk of capturing an unusually good or bad period for the company; with very long periods of time, the data could be less representative for the company.

${ }^{3}$ These markets are Australia, France, Germany, Hong Kong, Japan, United Kingdom, United States, China, India, Indonesia, Korea, Malaysia, Philippines, Thailand, Argentina, Brazil, Chile, Colombia, Mexico, Peru, and Venezuela.
} 
behavior. Pairwise correlations of herding measures are calculated among these markets. We also identify the pattern of herd behavior during sudden events such as the 1997-1998 global financial crisis. It is hypothesized that the outbreak of a financial crisis has a direct connection with the herding in the market. With the United States and Korea markets, Hwang-Salmon conclude that financial crises stimulate a return towards efficiency and investors turn to fundamentals rather than the overall market movement during market stress. We test this argument in a global setting with constituents of more financial markets.

To obtain the cross-sectional dispersion of the betas, we propose the use of the "right" beta of the CAPM or the linear factor model; a highly debated area in empirical finance. In this paper, we adopt a rolling robust regression approach to calculate the betas. The purpose of using robust regression is to diminish the influence of outliers on the point estimate of beta. To our knowledge, this paper is the first to calculate outlier-robust betas in emerging markets. ${ }^{4}$

The original framework of the CAPM is developed in a single-period setting. In most of the empirical studies, the beta is assumed to be constant over a defined period of time. However, this treatment of constant beta is contradicted by increasingly more evidence that beta is timevarying (Blume, 1971; Fabozzi and Francis, 1977; Fernandez, 2004). Several alternative models have been developed to capture the time-varying character of the beta: Fama and Macbeth (1973) propose a rolling regression approach to estimate the beta; Braun et al. (1995) use a bivariate EGARCH model to estimate a beta influenced asymmetrically by the market returns; Fama and French (1993) and Ferson and Harvey (1999) bring in macroeconomic variables to account for the beta; Faff and Brooks (1998) apply the Kalman filter approach to explain the stochastic evolution of the beta.

As for the accuracy of these alternative estimation methods, Groenewold and Fraser (2000) conclude that the rolling regression, although simple, is no less accurate than those more complicated models. Under the rolling regression, only one observation is new each month and therefore this overlapping problem leads to a high degree of autocorrelation in the beta time series. Regarding this, Groenewold and Fraser (2000) use non-overlapping sub-periods and conclude that this alteration does not change the results significantly. This evidence justifies the fact that rolling regression remains most popular among practitioners and in academic research. For instance, commercial resources such as Bloomberg Professional, Baseline, Value Line and Datastream provide betas of certain securities. Although each resource gives a different result for the beta of a security due to the several differences involved in the calculations, they typically use ordinary least squares (OLS) to regress the return of a security on a market index over a certain period, typically 2 to 5 years.

However, these conventional calculations of the CAPM beta fail to consider the existence of bivariate or multivariate outliers, which may be quite large in real data. These outliers have substantial influence on the OLS point estimate of beta. The differences between the OLS estimate and the robust estimate might be viewed as financially significant by investors.

\footnotetext{
${ }^{4}$ It is worth noting that outliers could be bad noise or the most important information-revealing aspect of the data. Hence further analysis of the identified outliers is necessary to provide more complete information. In other words, when influential outlier returns (containing important information) exist, neither the OLS betas nor the robust betas provide an adequate picture of the risk-return characteristics, and they may be combined to achieve more convincing results.
} 
Therefore, in calculating the rolling regression, we propose the robust estimation rather than the traditional OLS estimation.

We also calculate, in addition to the CAPM beta, the beta under the three-factor framework of Fama and French (1993). For comparison purposes, both the OLS and robust estimators are calculated. The establishment and analysis of Fama-French $H M L$ and $S M B$ factor for stock markets other than the United States help broaden our understanding of global portfolio management.

Time-varying herding measures allow us to discuss the concept of relative herding proposed in this paper. In brief, we find that herding towards the market is stronger in emerging markets than in developed markets. Additionally, we find that the herding measure, like some macroeconomic aggregate variables, follows a pattern of cycles, and some sudden events can sometimes be identified as turning points of the cycles. Furthermore, we do not observe any trend in the magnitude and the volatility of the herding measure over time. Finally, we see a higher correlation of herding between two markets from the same group than between markets from different groups. ${ }^{5}$

The remainder of the paper is organized as follows. Section I proposes the concept of relative herding and forms the hypotheses. Section II develops the model and introduces the Kalman filter, together with the robust regression technique used in this paper. Section III describes the data. Empirical results on the distribution of betas and herding patterns are discussed in Section IV. Section V closes the paper with concluding remarks and directions for future research.

\section{Herd Behavior in Financial Markets}

Various types of herding are discussed in both theoretical and empirical literature. In this paper, we focus on the evolution of herding towards the market index, a particular type of herding within the second stream of literature, as mentioned in the introduction. We will discuss how this type of herding affects the market and traditional asset pricing model in Section II.

\subsection{A Concept of "Relative Herding"}

In our opinion, no market is free of herd behavior. The notion of relative herding, i.e., measuring the herding of one market against another market or one period against another period, may be more useful than the all-or-nothing view taken by the conventional literature.

\subsubsection{Relative Herding: The Cross-Sectional Perspective}

Jirasakuldech et al. (2004) point out that high informational efficiency countries are associated with a lower level of equity market volatility, which, according to Christie and Huang (1995), is an indication of weak herd behavior in the market. Contrary to investors in developed markets, investors in newly established or emerging markets find it difficult or expensive to gather and collect information in order to conduct fundamental analysis. Instead, observing and imitating other investors' decision or the market index is relative easy and cheap and, as a result, herding can and often does ensue in emerging markets (Komulainen, 2001). Empirically, Choe et al.

\footnotetext{
${ }^{5}$ As will be seen later, we group the sample markets by their development stage and geographical location.
} 
(1999) show that the herd behavior that existed in the South Korean stock market eventually led to economic instability with the financial crisis in 1997; Komulainen (2001) and Chang et al. (2000) report the existence of herding in stock markets of South Korea and Taiwan.

Based on these studies, we build our first hypothesis as follows:

H1: Herding towards the market index is stronger in emerging than in developed markets.

\subsubsection{Relative Herding: The Time-Varying Perspective}

In this section we propose that herding measures fluctuate over time, and some turning points can be associated with the occurrence of sudden events. The study of the time-varying character of herding is loosely inspired by the business cycle theory in economics. ${ }^{6}$

Business cycle study has a long tradition in economics, referring to the periodic fluctuations of economic activity along with its long-term growth trend. There are many explanations for the existence of cycles. For instance, the psychological cycle explanation (by Arthur C. Pigou, among others) attributes it to the change of entrepreneurs' expectation of profits and confidence. It is assumed that the sense of optimism and pessimism motivates businesses to enlarge or contract investment. When the market is rife with optimistic expectation on consumptions, firms will attempt to increase production, leading to a general overshooting of output. This overshooting of output then results in an oversupply of goods, causing the bankruptcy of some firms, a general collapse in output, and a wave of pessimism. In turn, this will lead to an undersupply of goods, thereby paving the way for the next wave of optimism.

Any further discussion of business cycle is beyond the interest of this paper, since our purpose is to draw an analogy between the investors in stock markets and the entrepreneurs. Imagine that, when speculative prices in stocks or the whole market increase, the success story of some investors or the market index may attract public attention and promote word-of-mouth enthusiasm. Herding investors may thus become more herding-oriented, heightening expectations for further price increases. This process in turn increases investor demand and thus generates another wave of price increase. If the feedback is not interrupted, it may produce a speculative "bubble", in which high expectations, instead of fundamental values, support high current prices, thus making the bubble vulnerable and easy to burst, whereby people start changing their herd behavior. Since the feedback that propelled the bubble carries the seeds of its own destruction, the end of the bubble may be unrelated to new stories about fundamentals as well. A similar feedback process applies to negative bubbles. ${ }^{7}$ In combination, we can expect fluctuations in the herding towards the market; an interwoven mixture of upward and downward trends.

Like the observations in the business cycles, we predict that the lengths of the cycles in herding toward the market (from peak to peak, or from trough to trough) vary. Here, loosely following the definition of the macroeconomic business cycle by the Business Cycle Dating Committee of

\footnotetext{
6 In recent years economic theory has a trend of moving from the study of "business cycle" to "economic fluctuation", even though some economists still use the phrase "business cycle" as convenient shorthand.

7 Consistent with some combination of feedback effects and other demand factors driving the stock market independently of fundamentals, DeBondt and Thaler (1985) and Jegadeesh and Titman (1993) report that stock prices tend to continue in the same direction over short intervals of six months to a year, but to reverse themselves over longer intervals.
} 
the National Bureau of Economic Research (NBER), ${ }^{8}$ we identify a peak of herding as the beginning of a decrease which lasts more than certain months, and a trough as the beginning of an increase which lasts more than certain months.

We build the second hypothesis as follows:

H2: Herding, like some macroeconomic aggregate variables, follows a pattern of cycles. Some sudden events can be identified as turning points of the cycles.

To our knowledge, herding is an inherently coded human behavior, and it could be changed through the learning and experience of people. The increasingly easy procurement of information and the advancement of technology, among other factors, would attract more investors back to fundamental value of firms, thereby decreasing the magnitude of the herding. In other words, we expect to see a downward trend in the magnitude of the herding measure, accompanied by a decreasing volatility.

H3: There is a downward trend in the magnitude of herding measure and the volatility of the herding decreases over time.

\subsection{Correlation of Herd Behavior in Different Markets}

Hwang and Salmon (2004) find a low correlation between the herding of financial markets of United States and Korea. They conclude that market sentiment may not always be transferred internationally. This observation is interesting, given the fact that it is rather counterintuitive. Relevant questions arise naturally. For instance, is this low correlation between the United States and Korea the mainstream or just a special case in global markets? And if it is a special case, what is the main pattern we can expect on herding correlation? To answer these questions, a broader study, covering more sample markets, is necessary.

Aiken (2005) states that the more open an economy, the greater the influence that global equity markets have on changes in investor sentiment. Since the past two decades has witnessed the global trend of capital market liberalization and increasing cross-border investment, we have good reasons to expect that there is co-movement in herding between different markets. Due to the differences in market development stage, listed securities, market participants, investor philosophy, etc., the transfer of the herding sentiment may exhibit different patterns across different markets. We conjecture that herding is more correlated in financial markets with a similar development stage or economic characters. For instance, the positive correlation of herding in developed markets such as the United States and the United Kingdom is higher than that between the USA and Argentina. As will be seen in the data section, we divide our sample markets into three groups, covering major developed markets, emerging Asian markets, and emerging Latin American markets. The division is made, somewhat arbitrarily, by their development stage and geographical location.

H4: Herding sentiment towards the market travels across international markets. There is a higher correlation of herding between markets within the same group than between markets from different groups.

\footnotetext{
${ }^{8}$ For details of the NBER definition on business cycle, refer to "The NBERs Business-Cycle Dating Procedure", Business Cycle Dating Committee, National Bureau of Economic Research, October 2003.
} 


\section{The Methodology}

\subsection{Risk-Return Equilibrium with the Existence of Herding towards the Market}

The CAPM (Sharpe, 1964; Lintner, 1965) is widely used in defining the risk-return equilibrium relationship of equities. In the model, the market beta defines the return of equities. Not surprisingly, accumulating evidence shows that beta cannot be the sole variable to explain the equity returns. Fama and French (1993) develop their three-factor model (F-F model, hereafter) to incorporate factors associated with size and BE/ME. Fama and French (1996) further show that the F-F model can explain most of the departures from the CAPM predictions.

Basically, both the CAPM and the F-F model are within the risk-return framework: risk determines the asset return. However, Hirshleifer (2001) argues that the expected return of an asset is not only compensated by its fundamental risk, but also related to the investor misvaluation caused by cognitive imperfection of investors and social dynamics such as herding. In this section, we explore how the CAPM deviate from their original form with the existence of herding towards the market index. The conclusion also applies to the F-F model.

Our model of measuring herding is based on Hwang and Salmon (2004). They assume that the log of cross-sectional standard deviation of betas is normally distributed with a static mean. We argue against this assumption on two grounds. First, imposing assumptions on the crosssectional standard deviation of betas is not appropriate. Stock beta is actually derived from stock return, on which we usually make assumptions. Second, it is not obvious to us that the mean of the cross-sectional log standard deviation of the betas is static. Given the assumptions of this paper, we explore the distribution of the cross-sectional dispersion of betas after making additional assumptions on stock returns; by doing this, we get a time-varying series of the cross-sectional variance of beta, which we believe is more realistic than the static one.

\subsubsection{The model}

In essence, Hwang and Salmon (2004) measure herding on observed deviations from the equilibrium beliefs expressed in the CAPM. In a market with rational investors, the CAPM in equilibrium can be expressed as:

$$
\mathrm{E}_{\mathrm{t}}\left(r_{i t}\right)=\beta_{i t} \mathrm{E}_{\mathrm{t}}\left(r_{m t}\right)
$$

where $r_{i t}$ and $r_{m t}$ are the excess returns on asset $i$ and the market at time $t$ respectively; $\beta_{i t}$ is the systematic risk measure; and $\mathrm{E}_{\mathrm{t}}(\cdot)$ is the conditional expectation at time $t$.

We follow the assumption of Hwang-Salmon that investors form firstly the common marketwide view, $\mathrm{E}_{\mathrm{t}}\left(r_{m t}\right)$, and their behavior is then conditional upon it. When herding towards the market occurs, the investors shift their beliefs to follow the performance of the overall market more than they should in the CAPM. In other words, they ignore the equilibrium relationship in the CAPM and move towards matching the return on individual assets with that of the market. For instance, it is a common strategy that investors buy "underperforming" assets and sell "overperforming" assets. When herding towards the market occurs, if the market goes up significantly, then an asset with an intrinsic beta of 1.5 will become the target of selling, since its price increases more than the market index and looks more expensive. This selling of the asset leads to the decrease of the asset price. On the other hand, an asset with an intrinsic beta 
of 0.5 will become the target of buying, since its price increases less than the market index and looks cheaper. The buying of the asset leads to the increase of the asset price. Similar behavior happens when the market goes down significantly.

Thus, when there exists herding towards the market portfolio, the conventional CAPM no longer holds. The expected returns on the asset and the observed beta will be biased, and we denote them as $\mathrm{E}_{\mathrm{t}}^{\mathrm{b}}\left(r_{i t}\right)$ and $\beta_{i t}^{b}$, respectively. The mis-valuation mechanism can be described as follows.

When the market increases significantly, for an equity whose $\beta_{i t}$ is larger than one, $\mathrm{E}_{\mathrm{t}}\left(r_{i t}\right)>\mathrm{E}_{\mathrm{t}}\left(r_{m t}\right)$ as the CAPM says. However, the selling-herding of the investors will push the equity's price downward, making $0<\mathrm{E}_{\mathrm{t}}^{\mathrm{b}}\left(r_{i t}\right)<\mathrm{E}_{\mathrm{t}}\left(r_{i t}\right)$ and, therefore, $1<\beta_{i t}^{b}<\beta_{i t}$. For the same asset, when the market decreases significantly and thus $\mathrm{E}_{\mathrm{t}}\left(r_{i t}\right)<\mathrm{E}_{\mathrm{t}}\left(r_{m t}\right)$, as the CAPM predicts, buying-herding of the investors will push the asset's price upwards, making $\mathrm{E}_{\mathrm{t}}\left(r_{i t}\right)<\mathrm{E}_{\mathrm{t}}^{\mathrm{b}}\left(r_{i t}\right)<0$ and, therefore, $1<\beta_{i t}^{b}<\beta_{i t}$. The inverse process applies to the situation when $\beta_{i t}<1$, and, in this case, the biased beta will become larger when the market changes, i.e., $1>\beta_{i t}^{b}>\beta_{i t}$. An equity whose $\beta_{i t}=1$ is neutral to herding.

In other words, we are assuming that the biased beta follows a mean reverting process:

$$
\beta_{i t}^{b}=\mathrm{E}_{\mathrm{t}}^{\mathrm{b}}\left(r_{i t}\right) / \mathrm{E}_{\mathrm{t}}\left(r_{m t}\right)=\left(1-h_{t}\right) \beta_{i t}
$$

where $h_{t}$ is a latent herding parameter that changes over time. When $h_{t}=0$, there is no herding and the equilibrium CAPM holds; when $h_{t}=1$, there is perfect herding towards the market portfolio and all the individual assets move in the direction and with same magnitude as the market portfolio. In general, $0<h_{t}<1$, and some degree of herding exists. When $h_{t}<0$, there is reversed herding. ${ }^{9}$ Here, we assume that the investors implement the strategy on all equities, $h_{t}$ does not depend on $i$.

The form of herding under discussion represents market-wide behavior. So, it is preferable to use all assets in the market than a single asset to eliminate the effects of idiosyncratic movements in any individual $\beta_{i t}^{b}$. Then,

$$
\operatorname{var}_{c}\left(\beta_{i t}^{b}\right)=\left(1-h_{t}\right)^{2} \operatorname{var}_{c}\left(\beta_{i t}\right)
$$

where $\operatorname{var}_{c}(\cdot)$ is the cross-sectional variance.

In plain words, the existence of herding makes the cross-sectional dispersion of the individual betas smaller than it would be in equilibrium.

\footnotetext{
9 The opposite form of the behavior, called "adverse herding", could also happen when individual returns become more sensitive for large beta securities but less sensitive for low beta securities. In this case, high betas become higher and low betas become lower.
} 
Taking logarithms of Eq.3 on both sides,

$$
\log \left[\operatorname{var}_{c}\left(\beta_{i t}^{b}\right)\right]=\log \left[\operatorname{var}_{c}\left(\beta_{i t}\right)\right]+2 \log \left(1-h_{t}\right)
$$

We define $H_{t}=2 \log \left(1-h_{t}\right)$ and $\mu_{t}=\mathrm{E}\left(\log \left[\operatorname{var}_{c}\left(\beta_{i t}\right)\right]\right)$, and write

$$
\log \left[\operatorname{var}_{c}\left(\beta_{i t}\right)\right]=\mu_{t}+v_{t}
$$

where we assume $v_{t} \sim \operatorname{iid}\left(0, \boldsymbol{\sigma}_{\mathrm{v}}^{2}\right)$.

In Appendix I, we prove that $\log \left[\operatorname{var}_{c}\left(\beta_{i t}\right)\right]$ can be better approximated by a normal distribution with time-varying mean $\mu_{t}$, which is explained in the appendix.

If we estimate $\log \left[\operatorname{var}_{c}\left(\beta_{i t}^{b}\right)\right]$ with $\log \left[\operatorname{var}_{c}\left(\hat{\beta}_{i t}^{b}\right)\right]$, then Eq.4 can be rewritten as

$$
\log \left[\operatorname{var}_{c}\left(\hat{\beta}_{i t}^{b}\right)\right]=\mu_{t}+H_{t}+v_{t}
$$

We allow $H_{t}$ to evolve over time and assume it follows an AR(1) process:

$$
H_{t}=\phi H_{t-1}+\eta_{t}
$$

where $\eta_{t} \sim \operatorname{iid}\left(0, \boldsymbol{\sigma}_{\eta}^{2}\right)$.

The model is a standard state space model with Eq.7 as the measurement equation and Eq.8 as the transition equation. It can be estimated with the Kalman filter, which is briefly introduced in Appendix II. ${ }^{10}$

\subsection{The Calculation of Beta: A Robust Technique}

\subsubsection{Robust Estimate of the Beta}

Ordinary Least Squares (OLS) estimation is the most commonly-used technique in estimating beta. However, the OLS estimate has an obvious drawback, i.e., it can behave badly when the errors are not from a normal i.i.d. distribution, particularly when they are heavy-tailed, as revealed by the return data in the real financial world. It turns out that a few outliers can have a very strong influence on the OLS beta, thus leading to a distorted perspective on the relationship between equity returns and index returns. For instance, the fact that a small number of exceptionally large outlier returns giving rise to a beta of 3.0 does not justify an expectation of future return movement double that of the market. Under situations like this, robust estimation of beta can provide a better fit to the bulk of the equity returns versus index data (Martin and Simin, 1997). ${ }^{11}$

\footnotetext{
${ }^{10}$ For further introduction of Kalman filter, please refer to "Time series analysis by state space methods", 2001, by J. Durbin and S. Koopman, Oxford University Press.

${ }^{11}$ Despite their superior performance over least squares estimation in many situations, robust methods for regression are still very seldom used. One possible reason is that computation of robust estimates is much more demanding than least squares estimation, although this is no longer a problem given today's standard. Another reason for their lack of popularity may be that some popular statistical software packages failed to implement the methods (Stromberg, 2004). The belief of many statisticians that classical methods are robust (Hampel et al.,1986) also leads to the slow uptake of robust methods.
} 
The most applied method of robust regression is the M-estimation method, a generalization of maximum-likelihood estimation. Consider the linear model:

$$
y_{i}=X_{i} \beta+\varepsilon_{i}
$$

where $i=1, \ldots n$. The fitted model is:

$$
y_{i}=X_{i} b+e_{i}
$$

The M-estimate principle is to minimize the objective function:

$$
\sum_{i=1}^{n} \rho\left(e_{i}\right)=\sum_{i=1}^{n} \rho\left(y_{i}-X_{i} b\right)
$$

where the function $\rho(\cdot)$ gives the contribution of each residual to the objective function.

Define $\psi=\rho^{\prime}$ as the first-order derivative of $\rho$. By differentiating the objective function with respect to $b$ and setting the partial derivatives to 0 , we obtain a system of estimating equations:

$$
\sum_{i=1}^{n} \psi\left(y_{i}-X_{i} b\right) X_{i}{ }^{\prime}=0
$$

Defining the weight function as $w(e)=\psi(e) / e$ and letting $w_{i}=w\left(e_{i}\right)$, the estimating equations become:

$$
\sum_{i=1}^{n} w_{i} e_{i} X_{i}{ }^{\prime}=0
$$

Solving the estimating equations is a weighted least-squares problem, with the objective of minimizing $\sum_{i=1}^{n} w_{i}^{2} e_{i}^{2}$. The weights depend on the residuals, the residuals depend on the estimated coefficients, and the estimated coefficients depend on the weights. An iteration procedure is required to solve the problem.

In this paper, we apply Huber estimation, one of the most applied techniques in robust regression practice. See Appendix III for the comparison between the OLS estimation and the Huber estimation.

\subsubsection{Monte Carlo Experiments}

As an example, we perform Monte Carlo simulations for the following bivariate model to test whether or not the least square and Huber beta estimates are significantly different from each other:

$$
y_{i}=\alpha+\beta x_{i}+\varepsilon_{i}, \quad i=1, \ldots, N
$$

where the true $\alpha$ and $\beta$ are set to zero.

We try 10,000 Monte Carlo replicates of 100 observations of $\left(x_{i}, \varepsilon_{i}\right)$ for each of the following two situations. In the first situation, we use for every replicate a fixed set of $100 x_{i}$ 's, where $x_{i} \sim N(0,1)$, and 10,000 sets of $100 \varepsilon_{i}$ 's, where $\varepsilon_{i} \sim N(0,1)$. In the second situation, we use 
the same 10,000 replicate samples of $\left(x_{i}, \varepsilon_{i}\right)$, but we replace one (among 100) set of $\left(x_{i}, \varepsilon_{i}\right)$ with an independent pair of $\left(x_{i}, \varepsilon_{i}\right)$, where $x_{i} \sim N(5,2), \varepsilon_{i} \sim N(10,0.5)$. The results of the simulation are presented in Table 1 and Figure 1.

\section{Table 1}

Monte Carlo Simulated Betas with OLS and Robust Regression

\begin{tabular}{lccccc}
\hline Sample & Method & Mean & Std. Dev. & Skewness & Kurtosis \\
\hline \multirow{2}{*}{ without outliers } & OLS & 0.0015 & 0.102 & -0.023 & 3.09 \\
& Huber & -0.0013 & 0.104 & -0.024 & 3.07 \\
\hline \multirow{2}{*}{ with outliers } & OLS & 0.3785 & 0.142 & $-0.692^{*}$ & $3.86^{*}$ \\
& Huber & 0.0723 & 0.108 & 0.002 & 3.10 \\
\hline
\end{tabular}

* represents significance at $5 \%$ level.

Conditional on the value of the fixed independent variables $x_{i}$,

$\hat{\beta} \sim N\left(0, \sigma^{2} / \sum x_{i}{ }^{2}\right)=N(0,0.0102)$ when $\varepsilon_{i} \sim N(0,1)$. This normal density is overlaid as a reference in all the panels in Figure 1.

When both the independent variable and the error terms are normally distributed, as shown in the top panels in Figure 1, the histogram of the OLS estimate is very close to the theoretical normal distribution. The robust estimates also behave quite well, being reasonably normal in shape and well centered on zero, with a standard deviation slightly higher the OLS standard deviation. This increased standard deviation represents the lowered efficiency of robust regression when the errors are normal.

When the independent variable and the error terms are normally distributed but with outliers (bottom panels in Figure 1), the distribution of the OLS estimate is radically shifted in location and shape from the former situation when no outliers exist: The mean increases from 0.0015 to 0.3785 , the standard error increases from 0.102 to 0.142 , and the skewness decreases from -0.023 to -0.692 . On the contrary, the distribution of the robust estimates is very close to that obtained when there are no outliers. 


\section{Figure 1}

Monte Carlo Simulation for OLS and Robust Beta Estimates

The thick lines in the top two panels represent the histogram profile (10,000 replicates) of the distribution of the OLS, and Huber robust estimated beta when both the independent variable and the error terms are standard normally distributed. The bottom two panels show histogram profiles of the distribution when both the same data is used with the exception that there is one percent probability of an $\left(x_{o}, \varepsilon_{o}\right)$ outlier, where $x_{o} \sim \mathrm{N}(5,2)$, and $\varepsilon_{o} \sim \mathrm{N}(10,0.5)$. The overlaid density (thin line) is the "true" distribution of $N(0,0.0102)$.

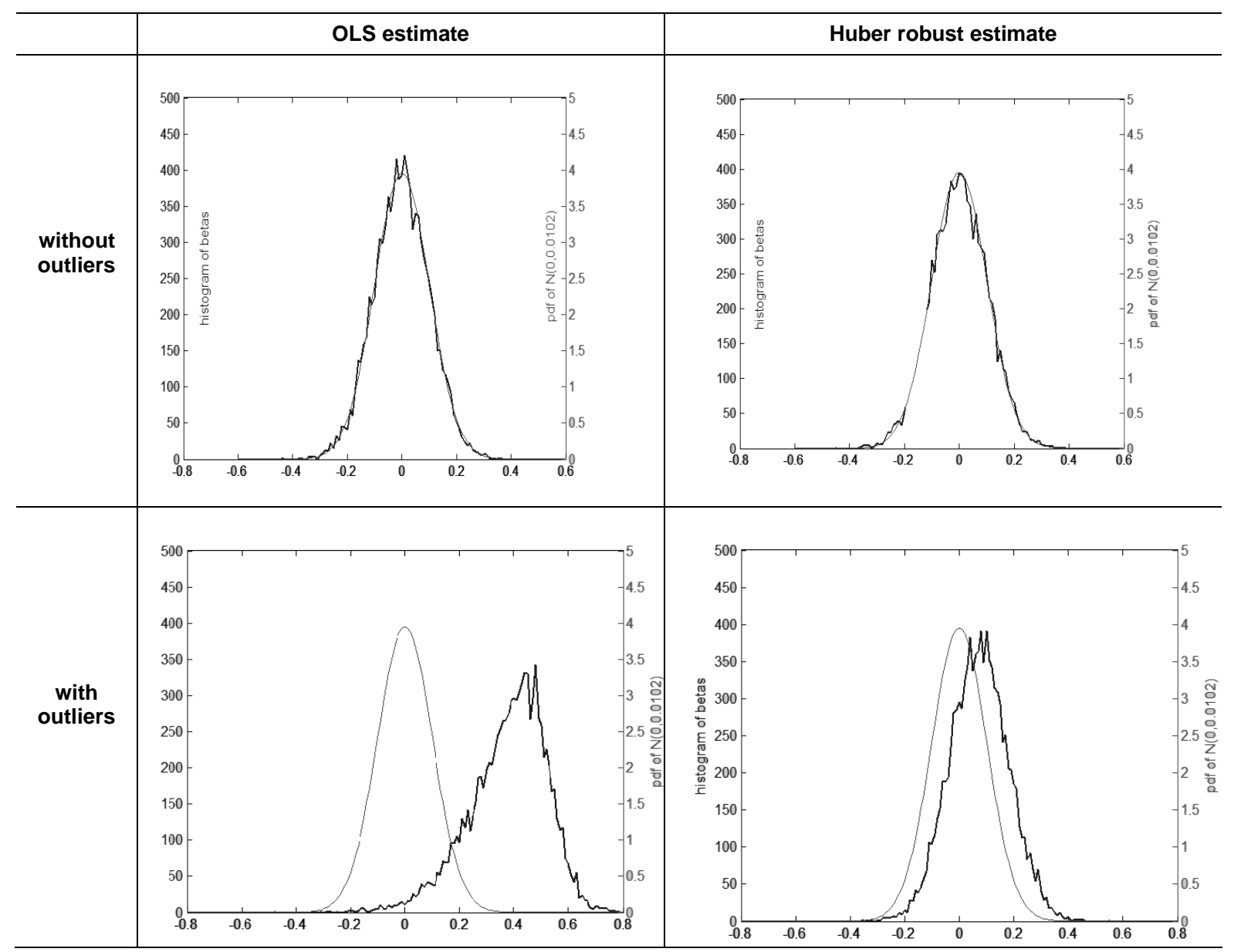

From this simple simulation, we can tell that robust regressions achieve almost the efficiency of OLS with ideal data while substantially better-than-OLS efficiency in non-ideal situations. ${ }^{12}$

\footnotetext{
${ }^{12}$ The existence of an outlier in our example is very obvious, even visually. For comparison purposes, we also run simulations when the outlier pair $\left(x_{i}, \varepsilon_{i}\right)$ is not obvious, for instance, $x_{i} \sim N(0,1.5)$ and $\varepsilon_{i} \sim N(1,0.5)$. In this case, we do not find a significant difference among the three techniques. Even so, we still give credentials to the robust techniques since, for large samples such as this paper, it is not possible to identify an outlier visually, although their existence might be very obvious.
} 


\section{The Data}

\subsection{Securities, Market Index and Proxy for Risk-Free Interest Rate}

Monthly total returns (in local currencies) of equities listed in the 21 stock markets are obtained from Datastream, covering the period from January of 1985 (or the earliest available date) to December of 2005. The 1997 Asian crisis, the 1998 Russian crisis, and the bull market until early 2001 and subsequent bear market are covered in the sample period.

We divide the 21 markets into three groups: the developed markets, the emerging Latin American markets, and the emerging Asian markets. Included in the developed markets are France, Germany, Hong Kong, Japan, United Kingdom, and the United States; included in the Latin American group are Argentina, Brazil, Chile, Colombia, Peru, Mexico, and Venezuela; and included in the Asian group are China, India, Indonesia, Korea, Malaysia, Philippines, and Thailand. The selected emerging markets are those marked as major emerging markets in EMDB of S\&P/COMPUSTAT.

In each market, the asset beta is calculated against a commonly-quoted market index. We have examined the correlation between these market indices and the Morgan Stanley Country Index (MSCI), which covers above 85 percent of the total market capitalization of each country. It turns out that the correlations are larger than 0.90 for all the markets except Brazil (0.761) and Peru (0.824). We can therefore conjecture that the results with these common market indices are not significantly different from those obtained with the MSCI. ${ }^{13}$

To calculate the excess market return, we approximate the risk-free rate of return with the short-term treasury bill rate and alternative short-term interest rate (if treasury bill rate is not available), which are obtained from Datastream and Global Financial Market Database. Table 2 lists the descriptive statistics of the above mentioned variables. All the markets (except China) have an average positive monthly return on market index, ranging between 8.14\% (Brazil) and $0.32 \%$ (Japan). The general rule of "high return vs. high return" pattern is observed in the market index change. A similar situation happens with the interest rate.

\footnotetext{
${ }^{13}$ According to Shanken (1987), if the correlation between the proxy and the true market exceeds about 0.7, then the rejection of the CAPM with a proxy would also lead to the rejection of the CAPM with the true market portfolio.
} 


\section{Table 2}

Descriptive Statistics of Equities on Sample Markets

\begin{tabular}{|c|c|c|c|c|c|c|c|c|}
\hline \multirow[b]{2}{*}{ Market } & \multirow[b]{2}{*}{ Time Period } & \multicolumn{4}{|c|}{ Monthly Market Index Change } & \multicolumn{3}{|c|}{ Risk-Free Interest Rate } \\
\hline & & Name & Mean & Std. Dev. & $\begin{array}{l}\text { Correlation with } \\
\text { MSCI Index }\end{array}$ & Type & Mean & Std. Dev. \\
\hline Australia (AUS) & Jan-85 to Dec-05 & $\mathrm{MSCl}$ & 0.0092 & 0.0491 & 1.000 & 3M-T-Bill & 0.0066 & 0.0033 \\
\hline France (FRA) & Jan-85 to Dec-05 & $\mathrm{MSCl}$ & 0.0101 & 0.0592 & 1.000 & 3M-T- Bill & 0.0048 & 0.0024 \\
\hline Germany (GER) & Jan-85 to Dec-05 & FAZ General & 0.0075 & 0.0561 & 0.986 & 3M-Benchmark Bond & 0.0036 & 0.0016 \\
\hline Hong Kong (HK) & Jan-85 to Dec-05 & Hang Seng Index & 0.0134 & 0.0803 & 0.978 & 1M-Deposit & 0.0040 & 0.0021 \\
\hline Japan (JAP) & Jan-85 to Dec-05 & NIKKEI 225 & 0.0032 & 0.0613 & 0.907 & 3M-T-Bill & 0.0019 & 0.0020 \\
\hline United Kingdom (UK) & Jan-85 to Dec-05 & FTSE All Share & 0.0073 & 0.0461 & 0.992 & 1M-T-Bill & 0.0060 & 0.0024 \\
\hline United States (USA) & Jan-85 to Dec-05 & S\&P 500 Composite & 0.0111 & 0.0446 & 0.999 & 3M-T-Bill & 0.0039 & 0.0016 \\
\hline China $(\mathrm{CHI})$ & Jan-94 to Dec-05 & $\mathrm{MSCl}$ & -0.0046 & 0.1113 & 1.000 & 3M- Deposit & 0.0025 & 0.0015 \\
\hline India (IND) & Jan-91 to Dec-05 & BSE National & 0.0169 & 0.0964 & 0.986 & 3M-T-Bill & 0.0071 & 0.002 \\
\hline Indonesia (INDO) & Jan-91 to Dec-05 & Jakarta SE Composite & 0.0095 & 0.0868 & 0.956 & 1M-Deposit & 0.0120 & 0.0069 \\
\hline Korea (KOR) & Jan-86 to Dec-05 & Korea SE Composite & 0.0131 & 0.0932 & 0.974 & 1M-Deposit & 0.0067 & 0.0021 \\
\hline Malaysia (MAL) & Jan-86 to Dec-05 & KLCI Composite & 0.0094 & 0.0852 & 0.992 & 1M-Deposit & 0.0038 & 0.0015 \\
\hline Thailand (THA) & Jan-89 to Dec-05 & Bangkok S.E.T. & 0.0080 & 0.1007 & 0.972 & 3M-Deposit & 0.0057 & 0.0034 \\
\hline Argentina (ARG) & Jan-92 to Dec-05 & Merval & 0.0122 & 0.1181 & 0.940 & 1M-Deposit & 0.0087 & 0.007 \\
\hline Brazil (BRA) & Jan-92to Dec-05 & Bovespa & 0.0814 & 0.186 & 0.761 & 3M-Deposit & 0.0093 & 0.0084 \\
\hline Chile (CHL) & Jan-90 to Dec-05 & IGPA & 0.0148 & 0.0584 & 0.961 & $1 \mathrm{M}-\mathrm{CD}$ & 0.0045 & 0.0017 \\
\hline Colombia (COL) & Jan-92 to Dec-05 & CSE & 0.0076 & 0.0385 & 0.913 & 3M -Deposit & 0.0150 & 0.0071 \\
\hline Mexico (MEX) & Jan-91 to Dec-05 & IPC (BOLSA) & 0.0223 & 0.0836 & 0.982 & 1M-CetesYield & 0.0133 & 0.0078 \\
\hline Peru (PER) & Jan-92 to Dec-05 & $\begin{array}{l}\text { Lima SE General } \\
\text { (IGBL) }\end{array}$ & 0.0288 & 0.1110 & 0.824 & 1M-Deposit & 0.0074 & 0.0043 \\
\hline \multirow[t]{2}{*}{ Venezuela (VEN) } & Jan-93 to Dec-05 & S\&P/IFCG & 0.0244 & 0.1187 & 0.952 & 1M-Deposit & 0.0179 & 0.0092 \\
\hline & & Average & 0.0149 & 0.0846 & 0.954 & & 0.0073 & 0.0039 \\
\hline
\end{tabular}

14 - IESE Business School-University of Navarra 


\section{Table 3}

Descriptive Statistics of Fama-French Three Factors

The factor values for the United States are from French's website. In other markets, we use the market index and risk-free rate described in Table 2 to obtain the excess market returns $\left(R_{m}-R_{b}\right)$. For the SMB and HML factors, we form the 6 size-BE/ME portfolios based on the equities from Datastream (the number of equities used are indicated in the third column). ", " and ${ }^{\dagger}$ represent significance at 1\%, 5\% and $10 \%$ level, respectively.

\begin{tabular}{|c|c|c|c|c|c|c|c|c|}
\hline \multirow{2}{*}{ Market } & \multirow{2}{*}{ Time Period } & \multirow{2}{*}{$\begin{array}{l}\text { No. of } \\
\text { Stocks }\end{array}$} & \multicolumn{2}{|c|}{$\mathbf{R}_{\mathrm{m}}-\mathbf{R}_{\mathrm{b}}$} & \multicolumn{2}{|c|}{$\mathbf{R}_{\text {SMB }}$} & \multicolumn{2}{|c|}{$\mathbf{R}_{\text {HML }}$} \\
\hline & & & Mean & $\begin{array}{l}\text { Std. } \\
\text { Dev. }\end{array}$ & Mean & $\begin{array}{l}\text { Std. } \\
\text { Dev. }\end{array}$ & Mean & $\begin{array}{l}\text { Std. } \\
\text { Dev. }\end{array}$ \\
\hline AUS & Jan-85 to Dec-05 & 1442 & 0.0026 & 0.0490 & $0.0217^{* *}$ & 0.0620 & 0.0001 & 0.0544 \\
\hline FRA & Jan-85 to Dec-05 & 770 & 0.0052 & 0.0593 & $0.0091^{* *}$ & 0.0416 & $0.0081^{* *}$ & 0.0486 \\
\hline GER & Jan-85 to Dec-05 & 1041 & 0.0040 & 0.0621 & $0.0103^{* *}$ & 0.0499 & $0.0060^{\dagger}$ & 0.0561 \\
\hline $\mathrm{HK}$ & Jan-85 to Dec-05 & 961 & $0.0096^{\dagger}$ & 0.0805 & $0.0196^{* *}$ & 0.0828 & $-0.0104^{*}$ & 0.0702 \\
\hline JAP & Jan-85 to Dec-05 & 3659 & 0.0013 & 0.0614 & $0.0077^{* *}$ & 0.0463 & 0.0011 & 0.0378 \\
\hline UK & Jan-85 to Dec-05 & 1723 & 0.0013 & 0.0461 & $0.0172^{* *}$ & 0.0537 & 0.0032 & 0.0306 \\
\hline USA & Jan-85 to Dec-05 & $N / A$ & $0.0072^{*}$ & 0.0445 & 0.0011 & 0.0315 & 0.0020 & 0.0359 \\
\hline $\mathrm{CHI}$ & Jan-94 to Dec-05 & 1557 & -0.0071 & 0.1114 & -0.0008 & 0.0999 & 0.0083 & 0.1377 \\
\hline IND & Jan-91 to Dec-05 & 490 & 0.0098 & 0.0967 & $0.0100^{*}$ & 0.0677 & 0.0109 & 0.0886 \\
\hline INDO & Jan-91 to Dec-05 & 319 & -0.0025 & 0.0876 & 0.0108 & 0.1179 & $0.0387^{* *}$ & 0.1447 \\
\hline KOR & Jan-86 to Dec-05 & 851 & 0.0064 & 0.0934 & $0.0108^{*}$ & 0.0740 & $0.0084^{\dagger}$ & 0.0748 \\
\hline MAL & Jan-86 to Dec-05 & 984 & 0.0055 & 0.0853 & 0.0063 & 0.0628 & 0.0060 & 0.0696 \\
\hline $\mathrm{PHI}$ & Jan-90 to Dec-05 & 241 & -0.0016 & 0.0919 & $0.0228^{* *}$ & 0.1004 & $0.0298^{* *}$ & 0.1158 \\
\hline THA & Jan-89 to Dec-05 & 498 & 0.0023 & 0.1010 & 0.0113 & 0.0988 & 0.0106 & 0.1153 \\
\hline ARG & Jan-92 to Dec-05 & 70 & 0.0036 & 0.1189 & 0.0056 & 0.0915 & $0.0169^{*}$ & 0.1011 \\
\hline BRA & Jan-92to Dec-05 & 478 & $0.0722^{* *}$ & 0.1810 & $0.0424^{* *}$ & 0.1512 & 0.0162 & 0.173 \\
\hline $\mathrm{CHL}$ & Jan-90 to Dec-05 & 196 & $0.0103^{*}$ & 0.0585 & 0.0053 & 0.055 & $0.0174^{* *}$ & 0.0724 \\
\hline $\mathrm{COL}$ & Jan-92 to Dec-05 & 35 & $-0.008^{* *}$ & 0.0392 & -0.0019 & 0.074 & $0.0198^{*}$ & 0.1118 \\
\hline MEX & Jan-91 to Dec-05 & 129 & 0.0089 & 0.0837 & 0.0063 & 0.0812 & 0.0017 & 0.1176 \\
\hline PER & Jan-92 to Dec-05 & 94 & $0.0214^{*}$ & 0.1102 & 0.0165 & 0.1313 & $0.0384^{* *}$ & 0.1827 \\
\hline \multirow[t]{2}{*}{ VEN } & Jan-93 to Dec-05 & 39 & 0.0065 & 0.1191 & -0.0023 & 0.1147 & 0.0054 & 0.1313 \\
\hline & & Average & 0.0076 & 0.0848 & 0.0105 & 0.0804 & 0.0118 & 0.0938 \\
\hline
\end{tabular}

\subsection{Fama-French Three Factors}

Since Fama-French factor values are only readily available for the United States at the website of Kenneth French, we calculate these factor values ourselves, and form the 6 size-BE/ME stock portfolios based on all the equities from Datastream. In forming the factors, we follow the method described in Fama and French (1993), with a minor modification: Since there are different financial reporting periods in these markets, we set the date of forming the portfolio in January of each year, instead of July in Fama and French. We conjecture that this modification will not change the results significantly. 


\section{Figure 2}

Fama-French Three Factors in Global Markets

The figures depict the scatterplot of the return vs. risk relationship for three factors in Fama-French model ( $a$ for excess market return, $b$ for $S M B$, and $c$ for $H M L$ ), with each point representing one of the 21 markets. A regression line plot is placed on top of each scatterplot.
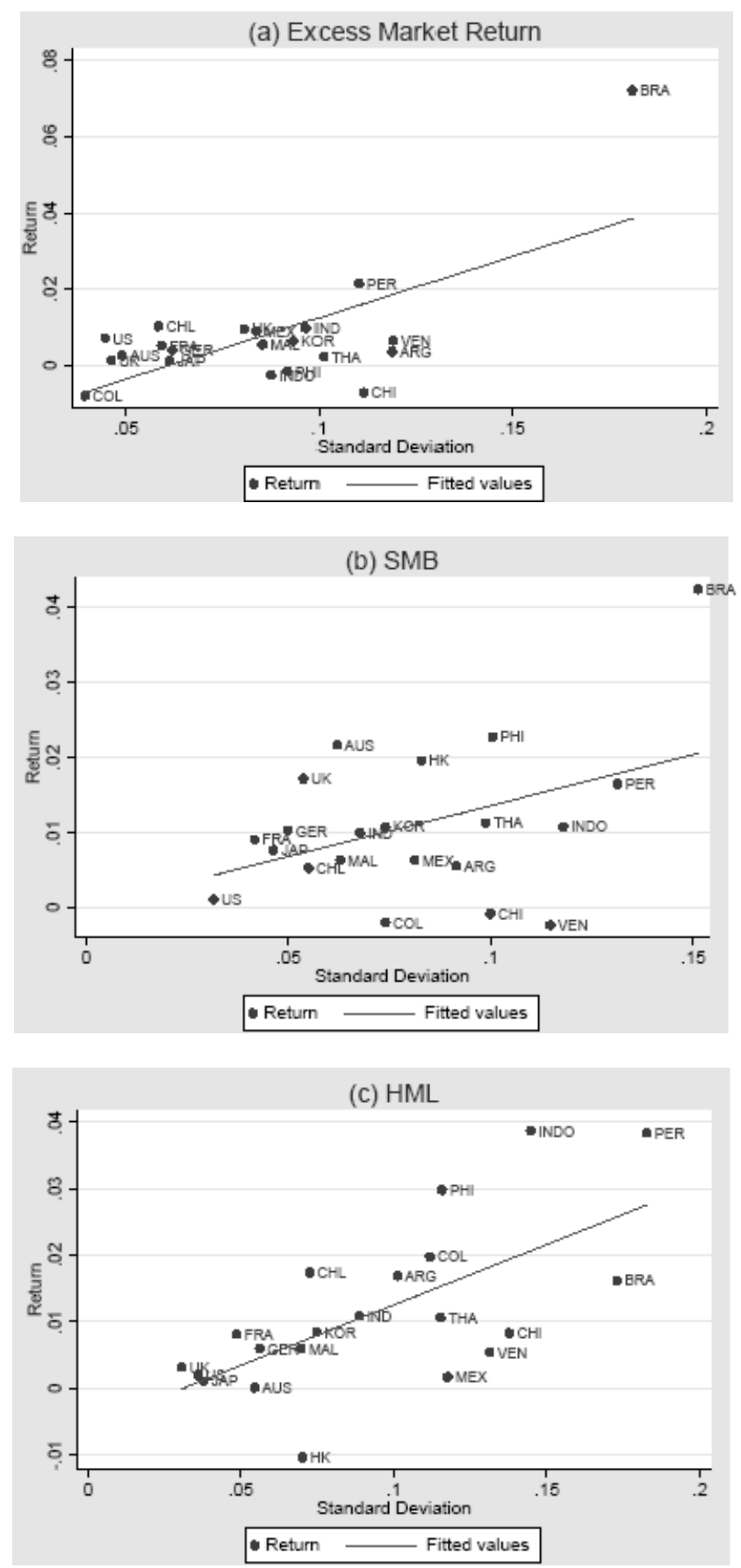

The descriptive statistics of the $S M B$ and $H M L$ for the sample markets are reported in Table 3. The third column in the table indicates the number of stocks used in forming the 6 size-BE/ME stock portfolios, which covers the majority of the stocks in each market. According to the table, the $S M B$ factor earns significantly positive returns for all developed markets (except the United States) and less than half of the total emerging markets. $H M L$ factor earns significantly positive 
returns for France, Germany and seven emerging markets. The excess market returns are not significantly different from zero for most of the markets. In exceptional cases, we observe significantly negative returns on the market factor (for Colombia) and on the HML factor (for Hong Kong). In other words, the strategy of investing on these factor portfolios over monthly horizons earns significant positive returns for some of the markets, insignificant positive returns for others, but negative returns for the very few others.

Figure 2 depicts the return vs. risk relationship for the three factors in all markets. A regression line plot is placed on top of the scatterplot. Basically, the return and the risk (represented by standard deviation) follow a positive linear pattern for each of the factors, with emerging markets on the high risk-high return end and developed markets on the low risk-low return end. It is interesting to point out that, for factors of excess market return and $S M B$, Brazil has a much higher average return than other countries, followed by its much higher standard deviation. Although we will not dwell on this, it is worth studying the potentials of expanding the efficient frontier in portfolio management by taking advantage of global financial markets.

\section{Empirical Results and Analysis on the Herd Behavior}

This section first reports the results on the beta estimation under CAPM and F-F model, respectively. Then we use the estimated betas to calculate the herding in each market. With the herding measure, we study the hypotheses developed in Section I, along with some discussions on other aspects of the herding.

\subsection{Estimated Cross-sectional Mean and Cross-sectional Variance of Betas}

Several filters are used in estimating betas of equities in these markets: First, first month's data for each security are deleted to eliminate the effect of IPO (Initial Public Offerings) underpricing. Second, securities with a history of less than 1.5 years are deleted. Third, observations with number of equities less than 10 percent of the number of equities at the endperiod are eliminated.

A set of monthly estimates of beta for all the equities in the sample are thus obtained for each market. Statistics of the betas of the CAPM and the F-F model, estimated with the robust Huber technique, are reported in Table 4. The large number of calculated betas (ranging from 2,118 in Venezuela to 953,058 in the United States) makes it possible for us to examine the distribution of the beta coefficients of the CAPM and the F-F model. We find that they are significantly different from zero in all cases, justifying the roles played by markets, size and BM/MV in explaining the cross-sectional equity returns.

Figure 3 depicts the evolution of the estimated cross-sectional mean of betas, $E_{c}\left(\hat{\beta}_{i t}^{b}\right)$, and the estimated cross-sectional variance of betas, $\operatorname{Var}_{c}\left(\hat{\beta}_{i t}^{b}\right)$, which are calculated as:

$$
\begin{aligned}
& E_{c}\left(\hat{\beta}_{i t}^{b}\right)=\sum_{i=1}^{N_{t}} \hat{\beta}_{i t}^{b} / N_{t} \\
& \operatorname{Var}_{c}\left(\hat{\beta}_{i t}^{b}\right)=\left(\hat{\beta}_{i t}^{b}-E_{c}\left(\hat{\beta}_{i t}^{b}\right)\right)^{2} /\left(N_{t}-1\right)
\end{aligned}
$$

where $N_{t}$ is the number of stocks at time $t$. 
Statistics about the two series are reported in Table 5. Under the CAPM, $E_{c}\left(\hat{\beta}_{i t}^{b}\right)$ for these market ranges between 0.243 (China) and 1.365 (Colombia), with a mean value of 0.776; $\operatorname{Var}_{c}\left(\hat{\beta}_{i t}^{b}\right)$ ranges between 0.058 (China) and 1.045 (Colombia), with a mean value of 0.301. Under the F-F model, $E_{c}\left(\hat{\beta}_{i t}^{b}\right)$ ranges between 0.354 (China) and 1.558 (Colombia), with a mean value of 0.838; $\operatorname{Var}_{c}\left(\hat{\beta}_{i t}^{b}\right)$ ranges between 0.044 (China) and 0.863 (Colombia), with a mean value of 0.320 .

The correlation between the cross-sectional variances of betas $\left(\operatorname{Var}_{c}\left(\hat{\beta}_{i t}^{b}\right)\right)$ obtained by CAPM and by F-F model ranges between 0.485 (United States) and 0.983 (Philippines), with a mean value of 0.887 . As the difference between the results with the CAPM and the F-F model does not seem to be large enough to change our interpretation of the herding measure, in the remaining of the paper, we only calculate the herding measure obtained with the F-F model. 


\section{Table 4}

Properties of the Robust Regression Betas

\begin{tabular}{|c|c|c|c|c|c|c|c|c|c|c|}
\hline & \multirow{3}{*}{ Sample Period } & \multirow{3}{*}{$\begin{array}{l}\text { No. of } \\
\text { betas }\end{array}$} & \multirow{2}{*}{\multicolumn{2}{|c|}{$\begin{array}{c}\text { The CAPM } \\
\beta\end{array}$}} & \multicolumn{6}{|c|}{ The F-F model } \\
\hline & & & & & \multicolumn{2}{|c|}{$\beta$} & \multicolumn{2}{|c|}{$\beta_{s m b}$} & \multicolumn{2}{|c|}{$\beta_{h m l}$} \\
\hline & & & Mean & Std. Dev. & Mean & Std. Dev. & Mean & Std. Dev. & Mean & Std. Dev. \\
\hline AUS & Jan-90 to Dec-05 & 109475 & 0.816 & 0.844 & 0.815 & 0.851 & 0.620 & 0.832 & 0.178 & 0.706 \\
\hline FRA & Jan-90 to Dec-05 & 76829 & 0.614 & 0.664 & 0.818 & 0.664 & 0.535 & 0.685 & 0.105 & 0.541 \\
\hline GER & Jan-90 to Dec-05 & 112701 & 0.591 & 0.586 & 0.783 & 0.712 & 0.492 & 0.721 & -0.027 & 0.560 \\
\hline HK & Jan-90 to Dec-05 & 92655 & 0.785 & 0.459 & 0.844 & 0.471 & 0.586 & 0.537 & -0.193 & 0.564 \\
\hline JAP & Jan-90 to Dec-05 & 452902 & 0.764 & 0.449 & 0.734 & 0.437 & 0.692 & 0.618 & 0.426 & 0.733 \\
\hline UK & Jan-90 to Dec-05 & 148710 & 0.857 & 0.659 & 0.895 & 0.651 & 0.537 & 0.624 & 0.106 & 0.743 \\
\hline USA & Jan-90 to Dec-05 & 953058 & 0.835 & 0.840 & 0.781 & 0.769 & 0.680 & 0.985 & 0.244 & 0.957 \\
\hline $\mathrm{CHI}$ & Jan-00 to Dec-05 & 85922 & 0.243 & 0.242 & 0.340 & 0.235 & 0.637 & 0.655 & -0.142 & 0.492 \\
\hline IND & Jan-96 to Dec-05 & 89584 & 0.862 & 0.464 & 0.916 & 0.461 & 0.560 & 0.630 & -0.210 & 0.430 \\
\hline INDO & Jan-96 to Dec-05 & 27397 & 0.926 & 0.555 & 0.920 & 0.54 & 0.331 & 0.456 & 0.203 & 0.350 \\
\hline KOR & Jan-93 to Dec-05 & 137852 & 0.816 & 0.412 & 0.973 & 0.433 & 0.639 & 0.539 & 0.062 & 0.538 \\
\hline MAL & Jan-93 to Dec-05 & 87680 & 1.164 & 0.425 & 0.983 & 0.355 & 0.734 & 0.540 & 0.394 & 0.504 \\
\hline $\mathrm{PHI}$ & Jan-95 to Dec-05 & 23206 & 0.831 & 0.584 & 0.900 & 0.587 & 0.371 & 0.485 & 0.152 & 0.393 \\
\hline THA & Jan-94 to Dec-05 & 46136 & 0.728 & 0.545 & 0.878 & 0.591 & 0.340 & 0.540 & 0.234 & 0.504 \\
\hline ARG & Jan-97 to Dec-05 & 6484 & 0.665 & 0.340 & 0.673 & 0.347 & 0.347 & 0.536 & 0.117 & 0.397 \\
\hline BRA & Jan-97 to Dec-05 & 31776 & 0.546 & 0.444 & 0.614 & 0.468 & 0.203 & 0.487 & 0.049 & 0.350 \\
\hline $\mathrm{CHL}$ & Jan-96 to Dec-05 & 18650 & 0.730 & 0.564 & 0.828 & 0.594 & 0.264 & 0.515 & 0.104 & 0.416 \\
\hline $\mathrm{COL}$ & Jan-97 to Dec-05 & 3389 & 1.352 & 0.957 & 1.530 & 0.959 & 0.130 & 0.415 & 0.055 & 0.310 \\
\hline MEX & Jan-96 to Dec-05 & 11508 & 0.612 & 0.438 & 0.669 & 0.455 & 0.269 & 0.466 & 0.124 & 0.334 \\
\hline PER & Oct-97 to Dec-05 & 8970 & 0.695 & 0.574 & 0.676 & 0.580 & 0.173 & 0.495 & 0.046 & 0.391 \\
\hline \multirow[t]{2}{*}{ VEN } & \multirow[t]{2}{*}{ Dec-97 to Dec-05 } & 2118 & 0.780 & 0.409 & 0.800 & 0.426 & 0.335 & 0.409 & 0.086 & 0.402 \\
\hline & & Average & 0.772 & 0.545 & 0.827 & 0.552 & 0.451 & 0.580 & 0.101 & 0.505 \\
\hline
\end{tabular}




\section{Figure 3}

Evolution of Cross-Sectional Mean and Variance of Betas

This figure shows the evolution of the cross-sectional mean and variance of the betas for the developed groups, Asian group and Latin American group, under the CAPM and the F-F model respectively. In each combinations of the graph, the top one is for the cross-sectional mean of the betas, and the bottom one for the cross-sectional variance of the betas.

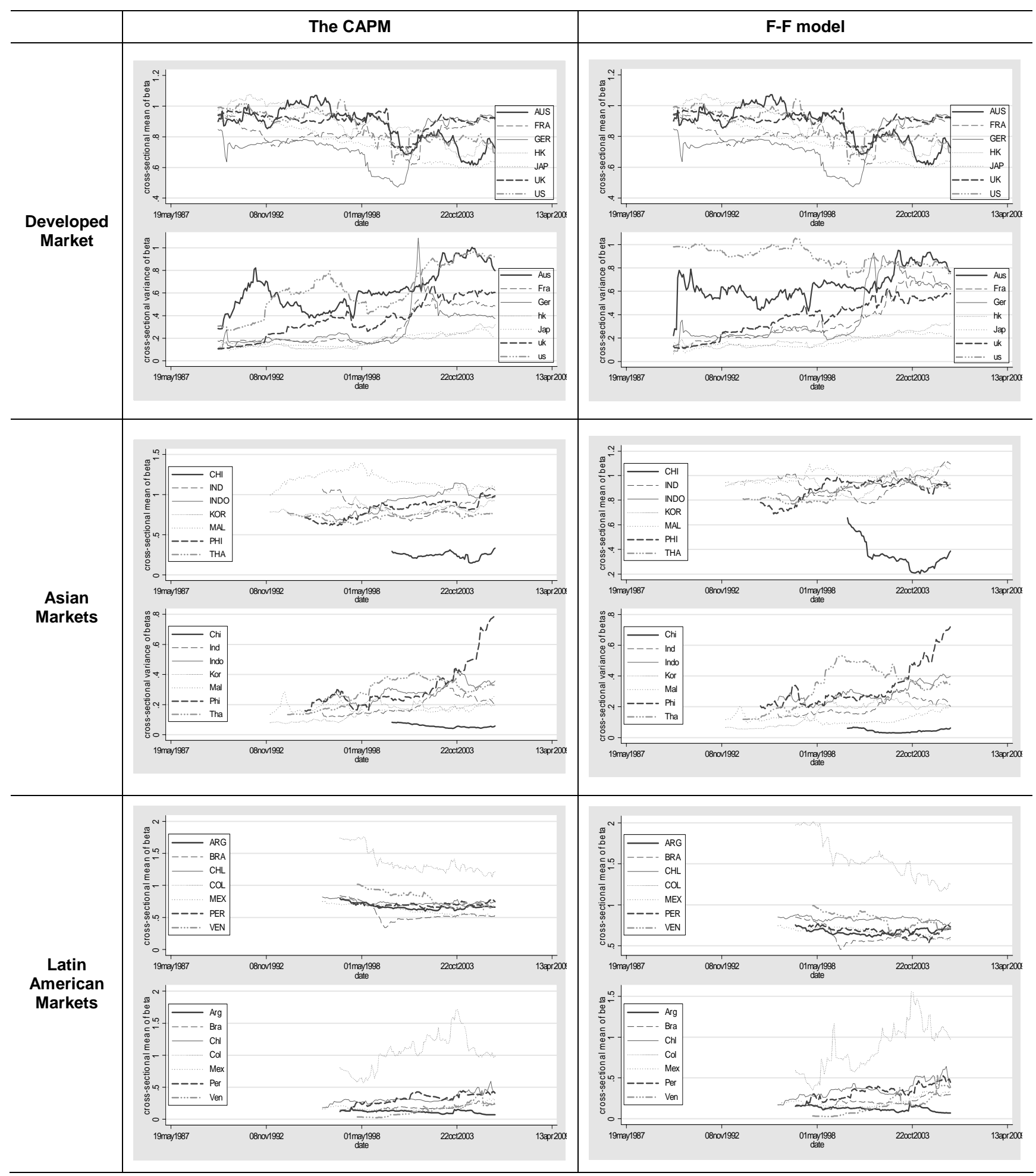




\section{Table 5}

Properties of the Cross-sectional Mean and Variance of the Betas

This table reports the first two moments of $\mathrm{E}_{\mathrm{c}}\left(\hat{\beta}_{i t}^{b}\right)$, the cross-sectional mean of the betas, and $\operatorname{Var}_{\mathrm{c}}\left(\hat{\beta}_{i t}^{b}\right)$, cross-sectional variance of the betas in each market, both under the CAPM and the F-F model. Column 6 and 11 show the correlation between the series calculated under the CAPM and the F-F model. The underlined values represent the minimum one in the series, and the italicized values represent the maximum one in the series.

\begin{tabular}{|c|c|c|c|c|c|c|c|c|c|c|}
\hline & \multicolumn{2}{|c|}{$\begin{array}{c}\left.\mathrm{E}_{\mathrm{c}}\left(\hat{\beta}_{i t}^{b}\right)\right|_{C A P M} \\
\text { (a) }\end{array}$} & \multicolumn{2}{|c|}{$\begin{array}{c}\left.\mathrm{E}_{\mathrm{c}}\left(\hat{\beta}_{i t}^{b}\right)\right|_{F-F} \\
\text { (b) }\end{array}$} & \multirow{2}{*}{$\begin{array}{l}\text { Correlation } \\
\text { between } \\
\text { (a) and (b) }\end{array}$} & \multicolumn{2}{|c|}{$\begin{array}{c}\operatorname{Var}_{\mathrm{c}}\left(\hat{\beta}_{i t}^{b}\right)_{C A P M} \\
\text { (c) }\end{array}$} & \multicolumn{2}{|c|}{$\begin{array}{c}\left.\operatorname{Var}_{\mathrm{c}}\left(\hat{\beta}_{i t}^{b}\right)\right|_{F-F} \\
\text { (d) }\end{array}$} & \multirow{2}{*}{$\begin{array}{l}\text { Correlation } \\
\text { between } \\
\text { (c) and (d) }\end{array}$} \\
\hline & Mean & $\begin{array}{l}\text { Std. } \\
\text { Dev. }\end{array}$ & Mean & $\begin{array}{l}\text { Std. } \\
\text { Dev. }\end{array}$ & & Mean & $\begin{array}{l}\text { Std. } \\
\text { Dev. }\end{array}$ & Mean & $\begin{array}{l}\text { Std. } \\
\text { Dev. }\end{array}$ & \\
\hline AUS & 0.816 & 0.058 & 0.869 & 0.119 & 0.345 & 0.626 & 0.180 & 0.653 & 0.134 & 0.824 \\
\hline FRA & 0.621 & 0.135 & 0.818 & 0.070 & 0.563 & 0.283 & 0.150 & 0.350 & 0.188 & 0.916 \\
\hline GER & 0.569 & 0.095 & 0.756 & 0.124 & 0.895 & 0.278 & 0.165 & 0.393 & 0.241 & 0.910 \\
\hline HK & 0.823 & 0.155 & 0.890 & 0.114 & 0.609 & 0.173 & 0.061 & 0.186 & 0.060 & 0.947 \\
\hline JAP & 0.786 & 0.105 & 0.764 & 0.115 & 0.897 & 0.179 & 0.053 & 0.168 & 0.048 & 0.969 \\
\hline UK & 0.840 & 0.119 & 0.901 & 0.062 & 0.405 & 0.367 & 0.160 & 0.377 & 0.148 & 0.954 \\
\hline USA & 0.859 & 0.081 & 0.867 & 0.101 & 0.829 & 0.626 & 0.210 & 0.793 & 0.077 & $\underline{0.485}$ \\
\hline $\mathrm{CHI}$ & 0.243 & 0.039 & $\underline{0.354}$ & 0.117 & 0.456 & $\underline{0.058}$ & $\underline{0.012}$ & $\underline{0.044}$ & $\underline{0.012}$ & 0.672 \\
\hline IND & $\overline{0.863}$ & 0.115 & $\overline{0.913}$ & 0.088 & 0.903 & $\overline{0.195}$ & $\overline{0.062}$ & $\overline{0.198}$ & $\overline{0.053}$ & 0.985 \\
\hline INDO & 0.907 & 0.133 & 0.911 & 0.056 & 0.956 & 0.285 & 0.057 & 0.286 & 0.058 & 0.886 \\
\hline KOR & 0.808 & 0.055 & 0.958 & 0.076 & 0.514 & 0.153 & 0.051 & 0.159 & 0.072 & 0.948 \\
\hline MAL & 1.177 & 0.092 & 0.979 & 0.038 & 0.428 & 0.173 & 0.028 & 0.124 & 0.030 & 0.829 \\
\hline $\mathrm{PHI}$ & 0.814 & 0.108 & 0.885 & 0.085 & 0.867 & 0.320 & 0.156 & 0.328 & 0.138 & 0.983 \\
\hline THA & 0.727 & 0.044 & 0.872 & 0.074 & 0.786 & 0.285 & 0.092 & 0.330 & 0.128 & 0.962 \\
\hline ARG & 0.665 & 0.045 & 0.673 & 0.035 & 0.753 & 0.116 & 0.023 & 0.122 & 0.029 & 0.925 \\
\hline BRA & 0.558 & 0.126 & 0.627 & 0.103 & 0.991 & 0.179 & 0.040 & 0.204 & 0.053 & 0.966 \\
\hline $\mathrm{CHL}$ & 0.730 & 0.038 & 0.828 & $\underline{0.027}$ & 0.517 & 0.319 & 0.076 & 0.350 & 0.100 & 0.946 \\
\hline $\mathrm{COL}$ & 1.365 & 0.184 & 1.558 & 0.242 & 0.926 & 1.045 & 0.268 & 0.863 & 0.288 & 0.817 \\
\hline MEX & 0.624 & 0.077 & 0.675 & 0.045 & 0.882 & 0.185 & 0.046 & 0.203 & 0.061 & 0.953 \\
\hline PER & 0.696 & 0.027 & 0.677 & 0.048 & $\underline{0.265}$ & 0.332 & 0.068 & 0.338 & 0.080 & 0.933 \\
\hline VEN & 0.797 & 0.113 & 0.813 & 0.094 & 0.895 & 0.145 & 0.099 & 0.159 & 0.121 & 0.815 \\
\hline Average & 0.776 & 0.093 & 0.838 & 0.087 & 0.699 & 0.301 & 0.098 & 0.320 & 0.101 & 0.887 \\
\hline
\end{tabular}

\subsection{The Properties of the Estimated Herding Measures}

We use the Kalman filter to estimate the herding indicator $\left(h_{t}=1-e^{H_{t} / 2}\right)$ with Eq.7 and Eq.8. The main results are reported in Panel $A$ of Table 6 . The average herding value ranges from 0.004 (United States) to 0.055 (Colombia), with an average of 0.031 .

As we have mentioned, the Kalman filter algorithm provides two series, a filtered one and a smoothed one. Here we only report the filtered series, since the smoothed one resembles the filtered one in all markets and does not alter our conclusions (the average correlation between the two series is as high as 0.97).

Figure 4 depicts the evolution of the herding measure in each market. A visual observation tells us there might be high correlation between two markets from the same group. For most of the markets, we see the trend from peak to trough over the period of early 1997 to early 1999 . We will check these points in the next section. 


\subsection{An Examination on the Herding Behavior}

\subsubsection{Cross-Sectional Comparison}

In order to check if there is difference in the magnitude of herding towards the market between emerging and developed markets, we run the two sample t-test on the mean of herding measures, as shown in Panel $B$ of Table 6. With a t-value of 11.41, we reject the null hypothesis that there is no difference in the mean of herding measure. ${ }^{14}$ In other words, the evidence support the hypothesis $\mathrm{H} 1$, and the emerging markets have a higher level of herding towards the market.

\section{Figure 4}

Evolution of Herding Measures

The figures depict the evolution of herding measure, obtained through the market betas of the F-F model, for the developed group, Asian group, and Latin American group.

(a) Developed Markets

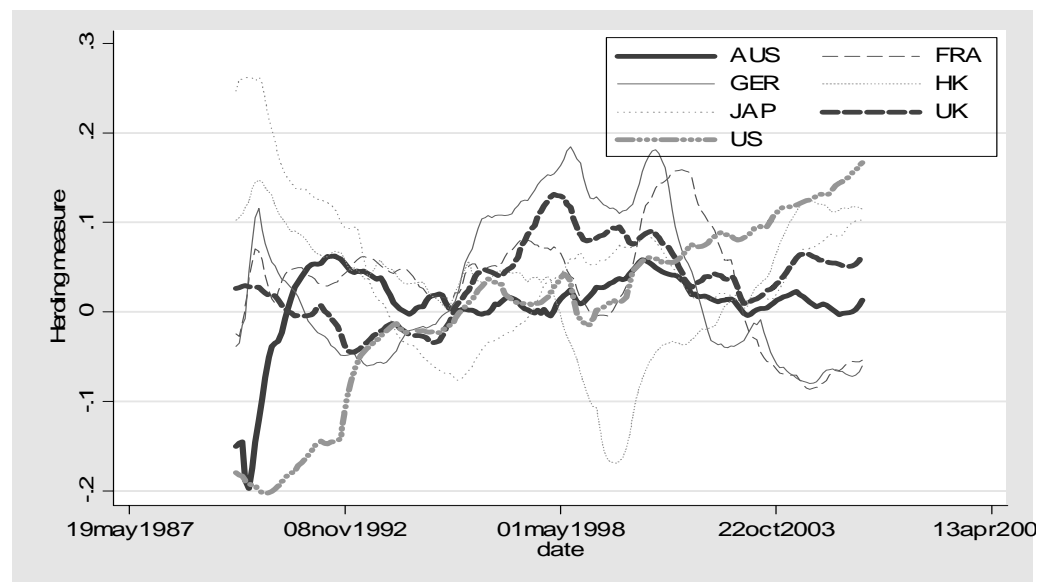

(b) Asian Markets



${ }^{14}$ Here we ignore the existence of autocorrelation in each series of herding measures, since we believe this will not significantly affect our test result. 
(c) Latin American Markets

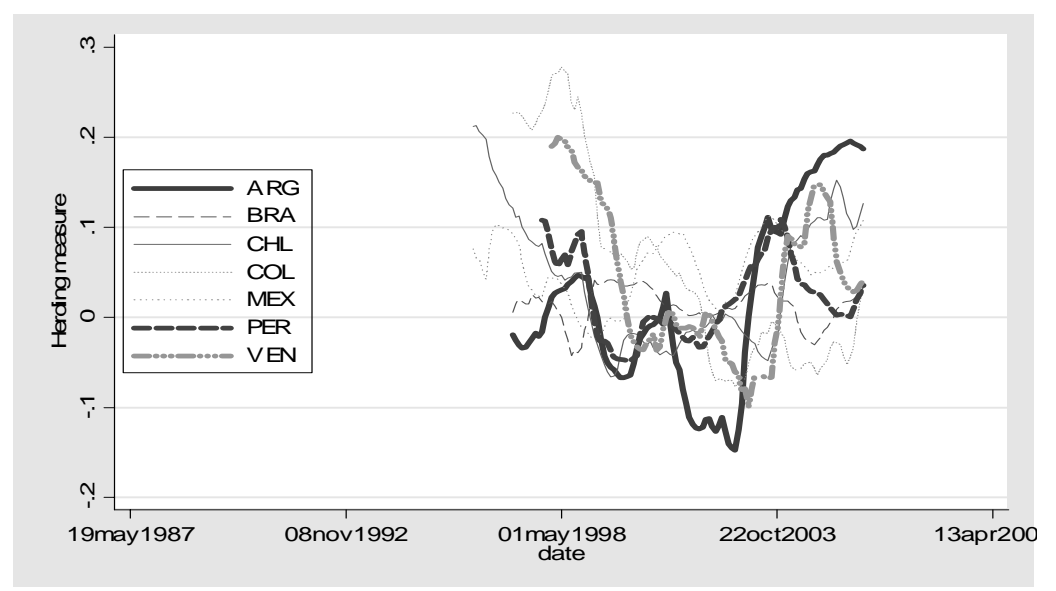

\section{Table 6}

Properties of the Herding Measure Estimated under the F-F model

Panel $A$ reports the Kalman filtered state space model of Eq.7 \& Eq.8. Column 6 lists the correlation between the Kalman filtered series and Kalman smoothed series. Panel $B$ tests the difference of the mean of herding between developed markets $\left(h_{t}^{\text {developed }}\right)$ and emerging markets $\left(h_{t}^{\text {emerging }}\right)$.

Panel A. Properties of Herding Measure in the Markets

\begin{tabular}{|c|c|c|c|c|c|}
\hline & \multicolumn{2}{|c|}{$h_{t}=1-e^{H_{t} / 2}$} & \multirow{2}{*}{$\phi$} & \multirow{2}{*}{$\begin{array}{c}\text { Maximum } \\
\text { likelihood } \\
\text { values }\end{array}$} & \multirow{2}{*}{$\begin{array}{l}\text { Correlation between } \\
\text { filtered series and } \\
\text { smoothed series }\end{array}$} \\
\hline & Mean & Std. Dev. & & & \\
\hline AUS & 0.010 & 0.011 & 0.997 & 5.29 & 0.976 \\
\hline FRA & 0.032 & 0.015 & 0.992 & 5.30 & 0.973 \\
\hline GER & 0.030 & 0.021 & 0.993 & 4.52 & 0.981 \\
\hline $\mathrm{HK}$ & 0.029 & 0.018 & 0.995 & 5.29 & 0.985 \\
\hline JAP & 0.051 & 0.019 & 0.998 & 4.30 & 0.991 \\
\hline UK & 0.036 & 0.011 & 0.993 & 5.79 & 0.983 \\
\hline USA & 0.004 & 0.025 & 0.999 & 5.85 & 0.997 \\
\hline $\mathrm{CHI}$ & 0.015 & 0.007 & 0.983 & 4.33 & 0.964 \\
\hline IND & 0.035 & 0.010 & 0.997 & 4.88 & 0.983 \\
\hline INDO & 0.033 & 0.011 & 0.986 & 4.83 & 0.965 \\
\hline KOR & 0.032 & 0.017 & 0.998 & 5.30 & 0.962 \\
\hline MAL & 0.041 & 0.027 & 0.994 & 5.10 & 0.984 \\
\hline $\mathrm{PHI}$ & 0.032 & 0.015 & 0.990 & 4.93 & 0.976 \\
\hline THA & 0.038 & 0.015 & 0.994 & 5.01 & 0.983 \\
\hline$A R G$ & 0.020 & 0.025 & 0.994 & 4.72 & 0.978 \\
\hline BRA & 0.013 & 0.005 & 0.954 & 4.73 & 0.885 \\
\hline $\mathrm{CHL}$ & 0.040 & 0.019 & 0.995 & 4.84 & 0.981 \\
\hline COL & 0.055 & 0.028 & 0.995 & 4.72 & 0.987 \\
\hline MEX & 0.053 & 0.009 & 0.977 & 4.83 & 0.927 \\
\hline PER & 0.021 & 0.011 & 0.977 & 4.83 & 0.944 \\
\hline VEN & 0.041 & 0.021 & 0.988 & 4.61 & 0.968 \\
\hline Average & 0.031 & 0.016 & 0.990 & 4.95 & 0.970 \\
\hline
\end{tabular}


Panel B. $t$ test on the difference of the mean of herding between developed and emerging markets

\begin{tabular}{lccc}
\hline Source & Observations & Mean & Std. Dev. \\
\hline$h_{t}^{\text {developed }}$ & 1344 & 0.027 & 0.015 \\
$h_{t}^{\text {emerging }}$ & 1659 & 0.034 & 0.018 \\
\hline $\mathrm{H}_{0}:$ mean $\left(h_{t}^{\text {developed }}\right)=$ mean $\left(h_{t}^{\text {emerging }}\right)$ & & \\
$\mathrm{H}_{\mathrm{a}}:$ mean $\left(h_{t}^{\text {developed }}\right)<$ mean $\left(h_{t}^{\text {emerging }}\right)$ & & \\
Result: $t$-value $=11.41, \mathrm{p}=0.00$ & & \\
\hline
\end{tabular}

\subsubsection{Turning Points of the Herding Measures}

The description of a cycle always starts with the identification of turning points in the series. There are various methods to accomplish this. In this paper, we follow the classic Bry and Boschan (1971) procedure.

In essence, the Bry-Boschan procedure is to isolate "true" turning points from some "false" turning points which are either short-lived or of insufficient amplitude. It starts with a highlysmoothed series to find initial estimates of local peak (trough) at time $t$, which is defined as the local maximum (minimum) over an interval from $t-k$ to $t+k$, where $k$ is generally set to five. These peaks and troughs must alternate. With these initial estimates, a less smoothed curve is investigated to refine the dates of the turning points. This process is then repeated with a shortterm ( 3 to 5 months) moving average. Final turning points are determined using the unsmoothed series, with a set of predefined restrictions; for instance, the cycle must be no less than 15 months in length and all phases must be over 5 months in duration. Interested readers are referred to King and Plosser (1989) for a detailed description of the procedure.

We apply the Bry-Boschan procedure to the herding measures, with a minor modification of removing the minimum length requirement on the cycle and the phase. Panel $A$ of Table 7 lists the months of peak and trough for each market. These turning points scatter without easily identifiable rules. Even so, we can tell that the majority of the markets have turning points between early 1997 and late 1998 when the 1997-1998 financial crisis broke out starting from Southeast Asia.

According to the table, developed markets have more turning points than emerging markets. We think it is due to the fact that the former has a longer sample history. We report the average length of cycle, calculated as twice of the arithmetic mean of monthly intervals from peak to trough, or trough to peak. Results show that the length ranges from 19 months (China) to 69 months (Thailand), with an average of 42 months.

Panel $B$ of Table 7 tests the null hypothesis that there are no differences among the average length of the cycles of the three groups. With an F-value of 2.21, we do not reject the null hypothesis at conventional levels.

In a nutshell, the evidence supports the hypothesis $H 2$ that herding follows a pattern of cycles, and sudden events such as financial turmoil can be identified as turning points of the cycles. 


\section{Table 7}

Turning Points of the Herding Measure

Panel $A$ lists the Bry-Boschan turning points of herding measures. $\mu_{L}$ represents the average length of the cycles, calculated as twice of the arithmetic mean of monthly intervals from peak to trough, or trough to peak. Panel $B$ tests the null hypothesis that there are no differences among the mean length of the cycles of the three groups. $\mu_{L}^{\text {Developed }}, \mu_{L}^{\text {Asian }}, \mu_{L}^{\text {LatinAmerican }}$ represent the average length of the cycles of the developed group, the Asian group, and the Latin American group, respectively.

Panel A. Turning Points

\begin{tabular}{llll}
\hline & Peak & Trough* & $\begin{array}{c}\text { Average length of the } \\
\text { cycles }\left(\mu_{L} \text {, month) }\right.\end{array}$ \\
\hline AUS & Feb90, Apr95, Oct97, Jun00, Apr04 & Mar91, Apr97, Sep98, Mar02 & 41 \\
FRA & Jan92, Aug97, Apr00, Feb02, Apr04 & Sep92, Jul98, Aug01, Jun03, Nov04 & 37 \\
GER & Oct91, Jul98, Dec04 & Jan90, Jun92, Feb02 & 68 \\
HK & Dec92, Jan98, Jun01, Jun04 & Apr96, Apr99, Jun03, Mar05 & 42 \\
JAP & Aug00, Jun04 & Aug95, Jul03, Apr05 & 58 \\
UK & Mar96, Oct99, May04 & Aug91, Jul97, Dec02 & 61 \\
USA & Feb94, Jun96, May98 & Oct90, Mar95, Jul97, Dec98 & 33 \\
CHI & Apr03, Nov04 & May04 & 19 \\
IND & Jun98, May00, Apr04 & Dec96, Jul99, May03, Nov04 & 32 \\
INDO & Apr97, Jul03 & Oct00, Jun04 & 57 \\
KOR & Dec96, Jul00, May04 & Dec98, Nov02 & 45 \\
MAL & Apr94, May97, Dec02 & Nov95, Jul01, May03 & 44 \\
PHI & Sep95, Jul97, Sep00, Aug04 & Dec96, Oct98, Jun03 & 36 \\
THA & Feb96, Jun97 & Oct99, Sep04 & 69 \\
ARG & Sep9, Dec00 & Nov99, Sep02 & 32 \\
BRA & Jul99, Jul03 & Jul98, Nov01, Sep04 & 37 \\
CHL & Feb00, Jun02, Apr05 & Jul99, Feb01, Jul03 & 28 \\
COL & Apr98, Jun00, Aug03 & Jan00, Sep02, Oct04 & 31 \\
MEX & Aug96, Feb01, Jul03 & Feb99, Apr02, Aug04 & 38 \\
PER & Jul00, Nov03 & Jan00, Oct01 & 31 \\
VEN & Nov04 & Jan03 & 44 \\
& & & 42 \\
\hline & & & Average \\
\hline
\end{tabular}

Panel B. One-way ANOVA F test for equality of the average length of herding cycle of each group

\begin{tabular}{lccc}
\hline Source & Observations & Mean & Std. Dev. \\
\hline$\mu_{L}^{\text {Developed }}$ & 7 & 48 & 13.5 \\
$\mu_{L}^{\text {Asian }}$ & 7 & 43 & 16.4 \\
$\mu_{L}^{\text {LatinAmerican }}$ & 7 & 34 & 5.5 \\
\hline $\mathrm{H}_{0}:$ Mean $\left(\mu_{L}^{\text {Developed }}\right)=\operatorname{Mean}\left(\mu_{L}^{A \text { Asian }}\right)=\operatorname{Mean}\left(\mu_{L}^{\text {LatinAmerican }}\right)$ & \\
$\mathrm{H}_{\mathrm{a}}:$ Not $\mathrm{H}_{0}$ & & \\
Result: F-value=2.21, $\mathrm{p}$-value $=0.14$ & & \\
\hline
\end{tabular}

* The first three characters represent the month and the last two digits represent the year. For instance, Feb90 means February, 1990. 


\subsubsection{The Volatility of the Herding Measures}

Figure 5 depicts the volatility of the herding measures $\left(\sigma_{h}^{2}\right)$ in the developed group, Asian group, and Latin American group, obtained through a GARCH(1,1) model. $\sigma_{h}^{2}$ fluctuates within a small range between 0 and 0.01 . There are several huge leptokurtics with peak value over 0.02 in the following markets: Australia (early 1990), Hong Kong (late 1999), Japan (early 1990), United States (early 1990), Korea (early 1999), Thailand (early 2000), Malaysia (early 2001), Chile (early 1996), Colombia (mid-1998), and Venezuela (mid-1998). No general withingroup trend can be observed in the figure. Thus, we do not find evidence to support hypothesis H3, i.e., the volatility of the herding decreases over time.

Panel $A$ of Table 8 reports the first two moments of the volatility of the herding measures. In panel $B$ of the table, we test the null hypothesis that the means of the volatility of the herding of the three groups are equal ( $\mu_{\sigma_{h}^{2}}^{\text {developed }}=\mu_{\sigma_{h}^{2}}^{\text {Asian }}=\mu_{\sigma_{h}^{2}}^{\text {LatinAmerican }}$ ). With an F-value of 2.69, we do not reject the null hypothesis at 5\% level of significance, although it is weakly rejected at $10 \%$ level.

\subsubsection{The Comovement of the Herding Measures}

The correlation coefficients of herding measures between various markets are shown in Table 9. Among the 210 pairwise correlation coefficients, 94 (46\%) are significantly positive, 61 (29\%) are significantly negative, while the remaining 55 (26\%) are non-significant. A closer look at the table reveals that most of the correlations between two countries from the same groups (e.g., Australia and France, Indonesia and India) are significantly positive, while the signs of the correlations between two countries from different groups (for instance, between China and Australia) are mixed. It is worth noting that, in the developed group, Japan, as the only case, has significant negative correlations with all the other markets. Similar situation happens to Brazil in the Latin American group.

Panel $A$ of Table 10 tests the equality between herding correlation within the groups (i.e., between countries in the same group) and those across the groups (i.e., between countries from different groups). The null hypothesis is that the mean within-group correlation is the same in all the groups. With a t-value of 3.60, we reject this hypothesis. 


\section{Figure 5}

Evolution of Volatility of Herding Measures

The figures depict the evolution of the volatility of the herding measures $\left(\sigma_{h}^{2}\right)$ for the developed group, Asian group, and Latin American group.

(a) Developed Markets

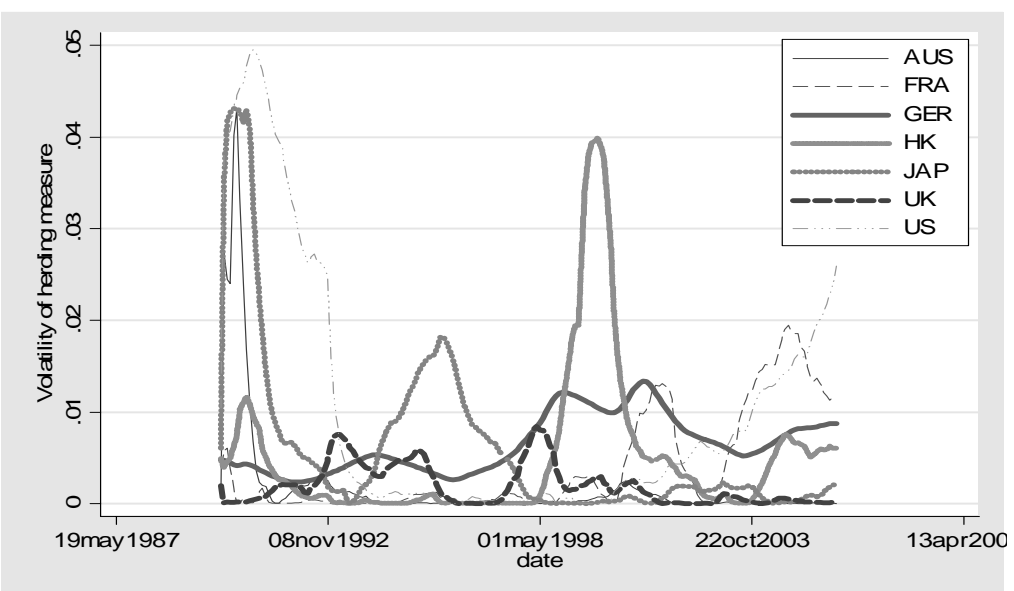

(b) Asian Markets

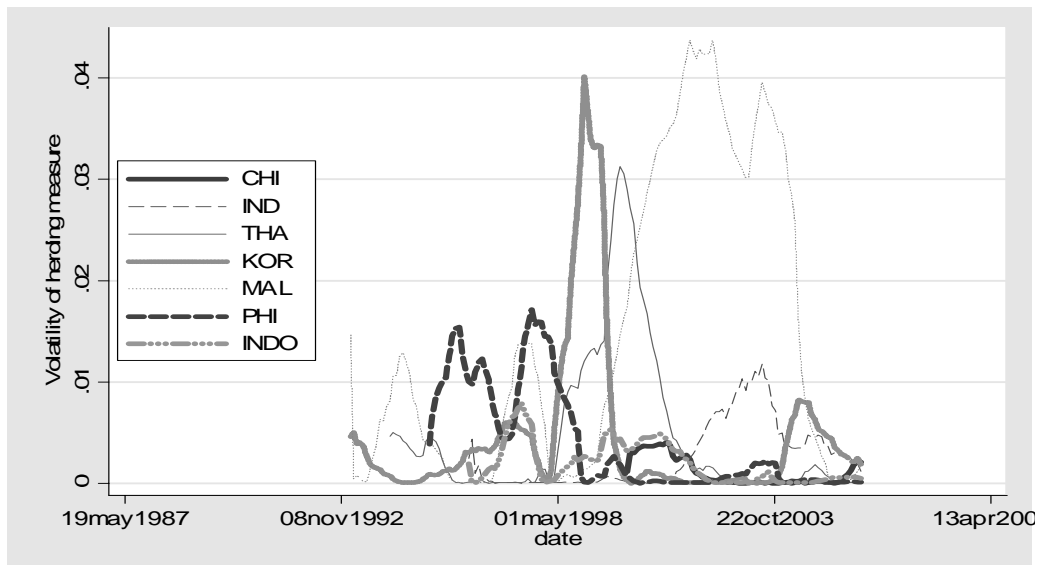

(c) Latin American Markets

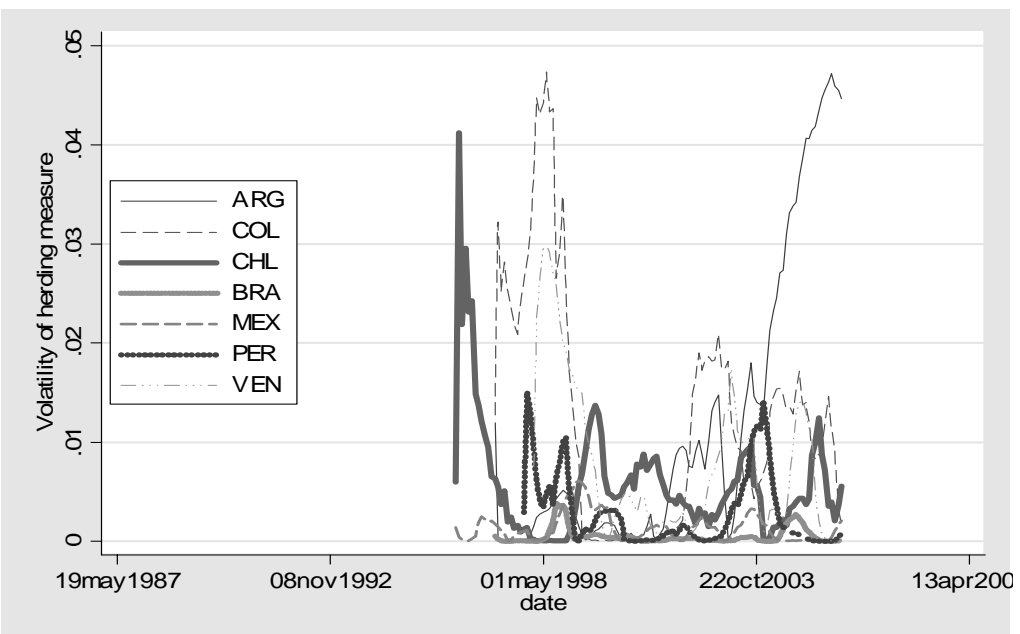




\section{Table 8}

Volatility of Herding Measures

Panel $A$ lists the mean and standard deviation for the variance of herding measure. Panel $B$ tests the null hypothesis that there are no differences among the means of herding volatility for the three groups.

Panel A. Descriptive Statistics of Herding Measure Volatility $\left(\sigma_{h, t}^{2}\right)$

\begin{tabular}{ccc|ccc|ccc}
\hline & Mean & $\begin{array}{c}\text { Std. } \\
\text { Dev. }\end{array}$ & & Mean & $\begin{array}{c}\text { Std. } \\
\text { Dev. }\end{array}$ & & Mean & $\begin{array}{c}\text { Std. } \\
\text { Dev. }\end{array}$ \\
\hline AUS & 0.0018 & 0.0061 & CHI & 0.0011 & 0.0014 & ARG & 0.0117 & 0.0146 \\
FRA & 0.0040 & 0.0056 & IND & 0.0027 & 0.0033 & BRA & 0.0005 & 0.0008 \\
GER & 0.0064 & 0.0031 & INDO & 0.0019 & 0.0021 & CHL & 0.0058 & 0.0060 \\
HK & 0.0061 & 0.0097 & KOR & 0.0045 & 0.0078 & COL & 0.0127 & 0.0122 \\
JAP & 0.0049 & 0.0084 & MAL & 0.0146 & 0.0150 & MEX & 0.0013 & 0.0015 \\
UK & 0.0020 & 0.0022 & PHI & 0.0039 & 0.0052 & PER & 0.0028 & 0.0037 \\
USA & 0.0104 & 0.0141 & THA & 0.0047 & 0.0075 & VEN & 0.0078 & 0.0077 \\
\cline { 2 - 3 } Average & $\mathbf{0 . 0 0 5 1}$ & $\mathbf{0 . 0 0 7 0}$ & Average & $\mathbf{0 . 0 0 4 8}$ & $\mathbf{0 . 0 0 6 0}$ & Average & $\mathbf{0 . 0 0 6 1}$ & $\mathbf{0 . 0 0 6 6}$ \\
\cline { 1 - 2 }
\end{tabular}

Panel B. One-way ANOVA F test for equality of the mean of herding volatility of each group

\begin{tabular}{lccc}
\hline Source & Observations & Mean & Std. Dev. \\
\hline$\sigma_{h, \text { Developed }}^{2}$ & 1344 & 0.0051 & 0.0084 \\
$\sigma_{h, \text { Asian }}^{2}$ & 900 & 0.0053 & 0.0092 \\
$\sigma_{h, \text { LatinAmerican }}^{2}$ & 759 & 0.0060 & 0.0093 \\
\hline
\end{tabular}

$\mathrm{H}_{0}: \mu_{\sigma_{h}^{2}}^{\text {developed }}=\mu_{\sigma_{h}^{2}}^{\text {Asian }}=\mu_{\sigma_{h}^{2}}^{\text {LatinAmerican }}$

$\mathrm{H}_{\mathrm{a}}$ : Not $\mathrm{H}_{0}$

Result: F-value $=2.69, p$-value $=0.07$ 


\section{Table 9}

Correlation Coefficient of Herding Measures

This table shows the correlation coefficients of herding measures from the Fama-French three-factor model. * represents significance at 5\% level. Among them, values in bold indicate significantly positive, and italicized values indicate significantly negative.

\begin{tabular}{|c|c|c|c|c|c|c|c|c|c|c|c|c|c|c|c|c|c|c|c|c|c|}
\hline & AUS & FRA & GER & HK & JAP & UK & USA & CHI & IND & INDO & KOR & MAL & PHI & THA & ARG & BRA & CHL & $\mathrm{COL}$ & MEX & PER & VEN \\
\hline AUS & 1.00 & & & & & & & & & & & & & & & & & & & & \\
\hline FRA & $0.71^{\star}$ & 1.00 & & & & & & & & & & & & & & & & & & & \\
\hline GER & $0.37^{\star}$ & $0.73^{*}$ & 1.00 & & & & & & & & & & & & & & & & & & \\
\hline HK & $0.36^{*}$ & -0.04 & -0.11 & 1.00 & & & & & & & & & & & & & & & & & \\
\hline JAP & $-0.38^{*}$ & $-0.29^{*}$ & $-0.23^{*}$ & -0.06 & 1.00 & & & & & & & & & & & & & & & & \\
\hline UK & $0.66^{*}$ & $0.80^{\star}$ & $0.74^{\star}$ & $-0.16^{\star}$ & -0.03 & 1.00 & & & & & & & & & & & & & & & \\
\hline USA & $0.90^{\star}$ & $0.53^{*}$ & $0.19^{\star}$ & $0.46^{*}$ & $-0.15^{*}$ & $0.49^{*}$ & 1.00 & & & & & & & & & & & & & & \\
\hline $\mathrm{CHI}$ & $-0.35^{*}$ & $-0.85^{*}$ & $-0.53^{*}$ & -0.02 & $-0.81^{*}$ & $-0.60^{*}$ & $0.51^{*}$ & 1.00 & & & & & & & & & & & & & \\
\hline IND & $-0.60^{*}$ & $0.84^{\star}$ & $0.88^{\star}$ & $-0.31^{*}$ & -0.22 & $0.56^{\star}$ & $-0.70^{*}$ & $-0.84^{*}$ & 1.00 & & & & & & & & & & & & \\
\hline INDO & -0.13 & -0.17 & -0.13 & 0.15 & $-0.73^{*}$ & $-0.67^{*}$ & $0.21^{*}$ & $0.79^{\star}$ & -0.13 & 1.00 & & & & & & & & & & & \\
\hline KOR & $0.54^{\star}$ & $-0.09^{*}$ & $-0.28^{*}$ & $0.33^{*}$ & -0.14 & $-0.50^{*}$ & $0.41^{*}$ & 0.19 & -0.16 & $0.58^{\star}$ & 1.00 & & & & & & & & & & \\
\hline MAL & $-0.45^{*}$ & $0.23^{*}$ & $0.49^{\star}$ & 0.05 & $-0.67^{*}$ & -0.11 & $-0.51^{*}$ & 0.09 & $0.58^{\star}$ & $0.58^{\star}$ & 0.09 & 1.00 & & & & & & & & & \\
\hline PHI & $-0.48^{*}$ & $0.50^{*}$ & $0.53^{\star}$ & 0.01 & $-0.69^{*}$ & -0.03 & $-0.55^{\star}$ & $-0.31^{*}$ & $0.40^{*}$ & $0.36^{\star}$ & $0.23^{*}$ & $0.75^{*}$ & 1.00 & & & & & & & & \\
\hline THA & $0.24^{\star}$ & $-0.50^{*}$ & $-0.40^{*}$ & $0.46^{\star}$ & $-0.64^{*}$ & $-0.77^{\star}$ & 0.10 & $0.81^{*}$ & $0.80^{*}$ & $0.80^{*}$ & $0.56^{*}$ & $0.45^{*}$ & $0.33^{*}$ & 1.00 & & & & & & & \\
\hline ARG & $0.20^{*}$ & $-0.53^{*}$ & 0.07 & $0.51^{*}$ & 0.08 & $-0.26^{*}$ & $0.59^{\star}$ & $0.32^{*}$ & -0.10 & $0.33^{*}$ & $0.30^{*}$ & $0.36^{*}$ & 0.01 & $0.46^{*}$ & 1.00 & & & & & & \\
\hline BRA & 0.12 & 0.19 & 0.05 & $-0.48^{*}$ & 0.08 & $0.22^{*}$ & -0.15 & $-0.38^{*}$ & 0.03 & -0.09 & -0.00 & -0.14 & $-0.35^{*}$ & $-0.35^{*}$ & $-0.21^{*}$ & 1.00 & & & & & \\
\hline $\mathrm{CHL}$ & $-0.22^{*}$ & 0.04 & $0.22^{\star}$ & $0.24^{\star}$ & $-0.56^{*}$ & $-0.37^{*}$ & 0.16 & $0.35^{\star}$ & $0.32^{*}$ & $0.67^{\star}$ & $0.49^{\star}$ & $0.74^{\star}$ & $0.62^{\star}$ & $0.61^{\star}$ & $0.63^{*}$ & $-0.47^{*}$ & 1.00 & & & & \\
\hline $\mathrm{COL}$ & $-0.79^{*}$ & $0.74^{\star}$ & $0.84^{\star}$ & -0.16 & $-0.30^{*}$ & $0.49^{*}$ & $-0.78^{\star}$ & $-0.85^{*}$ & $0.84^{\star}$ & -0.07 & $-0.42^{*}$ & $0.62^{*}$ & $0.76^{\star}$ & $-0.37^{*}$ & -0.17 & -0.05 & 0.08 & 1.00 & & & \\
\hline MEX & $0.49^{\star}$ & $-0.33^{*}$ & $-0.31^{*}$ & $0.37^{\star}$ & -0.13 & $-0.57^{*}$ & $0.47^{*}$ & -0.16 & $-0.20^{*}$ & $0.38^{*}$ & $0.67^{\star}$ & -0.07 & 0.01 & $0.50^{\star}$ & $0.37^{\star}$ & 0.15 & $0.20^{*}$ & $-0.30^{*}$ & 1.00 & & \\
\hline PER & $-0.21^{*}$ & $-0.42^{*}$ & 0.06 & $0.32^{\star}$ & $-0.63^{*}$ & $-0.31^{*}$ & 0.13 & $0.66^{\star}$ & -0.16 & $0.49^{\star}$ & -0.01 & $0.26^{*}$ & $0.43^{*}$ & $0.47^{\star}$ & $0.44^{*}$ & $-0.28^{*}$ & $0.31^{*}$ & $0.22^{\star}$ & $0.26^{*}$ & 1.00 & \\
\hline VEN & $-0.63^{*}$ & 0.19 & $0.65^{\star}$ & 0.11 & -0.06 & $0.42^{\star}$ & $-0.25^{\star}$ & $0.29^{\star}$ & $0.52^{\star}$ & -0.11 & $-0.41^{*}$ & $0.74^{\star}$ & $0.64^{\star}$ & -0.06 & $0.39^{\star}$ & $-0.50^{*}$ & $0.48^{\star}$ & $0.57^{\star}$ & $0.47^{\star}$ & $0.22^{\star}$ & 1.00 \\
\hline
\end{tabular}




\section{Table 10}

Test of Correlation Coefficients of Herding Measures among Various Groups

In Panel $A$, we tests the null hypothesis that the mean of pair wise herding correlation between countries from the same groups (i.e., for instance, Australia and France, China and India) is the same as the mean of pair wise correlation between countries from different groups (for instance, China and Australia). Panel $B$ is to test the null hypothesis that there are no differences among the means of the herding correlation between countries from the Developed group, from the Asian group, and from the Latin American group.

Panel A. Two-sample $t$ test for correlation coefficients within single group and between groups

\begin{tabular}{lcccc}
\hline Source & Observations & Mean & Std. Dev. & 95\% Confidence Interval \\
\hline Corr_within-group & 63 & 0.24 & 0.340 & {$[0.14,0.34]$} \\
Corr_between-group & 147 & 0.02 & 0.447 & {$[-0.06,0.09]$} \\
\hline \multicolumn{5}{r}{ : Mean(Corr_within-group)= Mean(Corr_between-groups) } \\
$\mathrm{H}_{\mathrm{a}}$ : Mean(Corr_within-group) > Mean(Corr_between-groups) \\
Result: t-value $=3.60$, p-value= 0.0002 \\
\end{tabular}

Panel B. One-way ANOVA F test for equality of the mean of herding correlation in each group

\begin{tabular}{lccc}
\hline Source & Observations & Mean & Std. Dev. \\
\hline Corr_Developed & 21 & 0.26 & 0.413 \\
Corr_Asian & 21 & 0.33 & 0.430 \\
Corr_Latin American & 21 & 0.13 & 0.341 \\
\hline
\end{tabular}

$\mathrm{H}_{0}$ : Mean(Corr_Developed $)=$ Mean(Corr_Asian) $=$ Mean(Corr_Latin American)

$\mathrm{H}_{\mathrm{a}}$ : Not $\mathrm{H}_{0}$

Result: F-value $=1.33, p$-value $=0.27$ 


\section{Table 11}

Correlation Coefficient of the First Difference of Herding Measures

This table shows the correlation coefficients of the first difference of herding measures from the Fama-French three-factor model. * represents significant at $5 \%$ level. Among them, values in bold indicate significantly positive, and italicized values indicate significantly negative.

The highlighted values (all of them are insignificant) indicate that their counterpart in Table 9 is significant at 5\% level.

\begin{tabular}{|c|c|c|c|c|c|c|c|c|c|c|c|c|c|c|c|c|c|c|c|c|c|}
\hline & AUS & FRA & GER & HK & JAP & UK & USA & $\mathrm{CHI}$ & IND & INDO & KOR & MAL & PHI & THA & ARG & BRA & $\mathrm{CHL}$ & COL & MEX & PER & VEN \\
\hline AUS & 1.00 & & & & & & & & & & & & & & & & & & & & \\
\hline FRA & $0.33^{*}$ & 1.00 & & & & & & & & & & & & & & & & & & & \\
\hline GER & $0.19^{\star}$ & 0.11 & 1.00 & & & & & & & & & & & & & & & & & & \\
\hline $\mathrm{HK}$ & $0.27^{\star}$ & 0.06 & $0.19^{\star}$ & 1.00 & & & & & & & & & & & & & & & & & \\
\hline JAP & 0.12 & $0.20^{*}$ & $0.16^{*}$ & $0.23^{*}$ & 1.00 & & & & & & & & & & & & & & & & \\
\hline UK & $0.32^{*}$ & $0.20^{*}$ & $0.15^{*}$ & $-0.16^{*}$ & $0.32^{*}$ & 1.00 & & & & & & & & & & & & & & & \\
\hline USA & $0.53^{\star}$ & 0.11 & $0.28^{*}$ & $0.26^{*}$ & 0.10 & 0.06 & 1.00 & & & & & & & & & & & & & & \\
\hline $\mathrm{CHI}$ & $-0.32^{*}$ & -0.17 & -0.15 & $-0.36^{*}$ & -0.23 & 0.34 & $-0.39^{*}$ & 1.00 & & & & & & & & & & & & & \\
\hline IND & 0.01 & 0.03 & 0.15 & 0.03 & 0.13 & -0.08 & 0.11 & $-0.38^{\star}$ & 1.00 & & & & & & & & & & & & \\
\hline INDO & -0.17 & 0.05 & -0.17 & -0.13 & $-0.39^{*}$ & $-0.32^{*}$ & -0.05 & 0.15 & 0.03 & 1.00 & & & & & & & & & & & \\
\hline KOR & $0.35^{\star}$ & $0.28^{\star}$ & 0.05 & 0.13 & 0.11 & -0.01 & 0.13 & -0.15 & 0.05 & $0.22^{\star}$ & 1.00 & & & & & & & & & & \\
\hline MAL & $0.24^{\star}$ & $0.24^{\star}$ & 0.07 & $0.17^{\star}$ & -0.10 & -0.05 & -0.13 & 0.03 & 0.06 & $0.38^{\star}$ & $0.18^{\star}$ & 1.00 & & & & & & & & & \\
\hline $\mathrm{PHI}$ & 0.07 & 0.05 & 0.13 & $0.34^{*}$ & 0.05 & -0.04 & 0.15 & -0.09 & 0.09 & -0.05 & $0.21^{*}$ & 0.01 & 1.00 & & & & & & & & \\
\hline THA & 0.04 & 0.02 & -0.13 & $0.27^{\star}$ & $-0.19^{*}$ & -0.12 & 0.03 & 0.08 & -0.10 & $0.23^{*}$ & 0.04 & $0.27^{\star}$ & $0.19^{\star}$ & 1.00 & & & & & & & \\
\hline ARG & 0.03 & $-0.27^{*}$ & $0.41^{*}$ & $0.22^{*}$ & 0.07 & 0.05 & 0.03 & -0.09 & 0.15 & -0.04 & -0.02 & 0.04 & 0.04 & 0.07 & 1.00 & & & & & & \\
\hline BRA & 0.17 & 0.15 & -0.09 & -0.09 & -0.14 & 0.16 & -0.07 & -0.12 & 0.02 & 0.15 & 0.06 & 0.01 & $-0.27^{*}$ & -0.04 & 0.02 & 1.00 & & & & & \\
\hline $\mathrm{CHL}$ & 0.06 & 0.16 & 0.01 & $0.19^{*}$ & -0.04 & -0.15 & 0.08 & 0.12 & $0.37^{\star}$ & -0.01 & 0.19 & 0.16 & $0.35^{\star}$ & 0.03 & 0.00 & $-0.28^{*}$ & 1.00 & & & & \\
\hline $\mathrm{COL}$ & -0.13 & -0.13 & 0.10 & $0.20^{*}$ & 0.07 & -0.04 & -0.01 & -0.05 & 0.21 & -0.02 & -0.03 & 0.09 & 0.15 & 0.01 & -0.09 & -0.10 & 0.03 & 1.00 & & & \\
\hline MEX & 0.15 & -0.16 & -0.01 & $0.23^{\star}$ & -0.03 & -0.17 & $0.23^{*}$ & $-0.33^{*}$ & 0.13 & -0.04 & 0.15 & -0.10 & -0.11 & 0.15 & $0.31^{*}$ & 0.19 & $-0.23^{*}$ & 0.18 & 1.00 & & \\
\hline PER & 0.15 & -0.18 & 0.17 & 0.16 & 0.17 & 0.01 & -0.04 & 0.04 & 0.07 & -0.23 & -0.06 & -0.06 & $0.20^{*}$ & -0.03 & 0.19 & $-0.23^{*}$ & 0.14 & $0.29^{*}$ & 0.14 & 1.00 & \\
\hline VEN & $-0.31^{*}$ & -0.03 & 0.08 & 0.09 & 0.08 & $0.22^{\star}$ & 0.13 & $0.33^{\star}$ & 0.09 & -0.10 & $-0.35^{\star}$ & -0.09 & 0.11 & $0.21^{\star}$ & 0.15 & -0.10 & 0.09 & 0.12 & -0.15 & -0.12 & 1.00 \\
\hline
\end{tabular}


Panel $B$ of Table 10 tests the equality of the means of the herding correlation of the groups, with a null hypothesis of equal mean. With an $F$-value of 1.33 , we do not reject the null hypothesis at any conventional level of significance.

To check whether the above correlation is spurious, we calculate the correlation of the first difference of the herding measures, $\Delta h_{t}\left(=h_{t}-h_{t-1}\right)$. The result is reported in Table 11. Now, among the 210 pair wise correlation coefficients, 43 are significantly positive, 16 are significantly negative, while the remaining 151 are insignificant. The highlighted values in the table (all of them are non-significant) indicate that their counterparts in Table 9 are significant at 5\% level. From the table, a majority of the correlations in the developed group keeps its original level of significance at Table 9, so it is highly unlikely that the correlations of the original series within the groups are spurious. On the other hand, since most of the correlations between markets from different groups are no longer significant, we cast doubt on the significance of correlations between two markets from different groups.

In sum, we find support for the hypothesis $H 4$, i.e., the correlation of herding between markets from the same group is higher that that between markets from different groups.

\section{Conclusions}

In this paper, we use the cross-sectional variance of the betas to study herd behavior towards market index in major developed and emerging financial markets. We propose using a robust regression technique to calculate the betas of the CAPM and those of the Fama-French threefactor model, in order to diminish the impact of multivariate outliers on return data. Through the estimates derived from a state space model, we examine the evolution and cross-sectional relationship of the herding measures, especially their pattern around sudden events such as the 1997-1998 financial crisis.

As a result, we find a higher level of herding in emerging markets than in developed markets. Additionally, the herding measure, like most macroeconomic aggregate variables, follows a pattern of cycles. And some sudden events, such as the 1997-1998 financial turmoil, can be identified as turning points of the cycles. Furthermore, we do not observe any trend in the magnitude and the volatility of the herding measure over time. Finally, we witness a higher correlation of herding between two markets from the same group than those from different groups.

One direct question related to this paper is: What are the possible factors influencing the herd behavior towards the market? To answer this question, future research is suggested on the robustness check of this paper's conclusion, in the presence of variables reflecting either the state of the market, for instance, the market volatility and macroeconomic fundamentals, or the history and cultural ingredients.

Given the fragility of emerging financial markets, it is imperative to study the effect of policy change in capital markets on herd behavior in these markets. For instance, is there an impact of financial market liberalization on the herd behavior of investors? Has the herd behavior been weakened or strengthened by the liberalization?

Other interesting questions include: Why, in the developed group, does Japan have negative herding correlations with all the other developed markets? Do professional investors like mutual funds show different herding pattern from individual investors? 


\section{Appendix I}

The Distribution of Cross-Sectional Dispersion of Betas

According to the APT, the excess return of asset $i$ follows the linear factor model:

$$
\mathbf{R}_{\mathrm{it}}=\sum_{k=1}^{\mathrm{K}} \beta_{i k t} \mathbf{F}_{\mathbf{k t}}+\varepsilon_{i t} \quad i=1, \ldots, \mathrm{N}_{\mathrm{t}} \text { and } t=1, \ldots, \mathrm{T}
$$

where factor $\mathbf{F}_{\mathbf{k}}$ is assumed to be uncorrelated $(k=1, \ldots, \mathrm{K})$, and $\varepsilon_{i}$ is uncorrelated across assets.

One factor used actually in all models is $\mathbf{R}_{\mathrm{mt}}$, the excess market portfolio return, and Eq.A-1 can be written as:

$$
\mathbf{R}_{\mathrm{it}}=\beta_{i t} \mathbf{R}_{\mathrm{mt}}+\sum_{k=1}^{\mathrm{K}-1} \beta_{i k t} \mathbf{F}_{\mathbf{k t}}+\varepsilon_{i t}
$$

Taking cross-sectional expectation on both sides:

$$
\mathrm{E}_{\mathrm{C}}\left(\mathbf{R}_{\mathrm{it}}\right)=\mathrm{E}_{\mathrm{C}}\left(\beta_{i t}\right) \mathbf{R}_{\mathrm{mt}}+\sum_{k=1}^{\mathrm{K}-1} \mathrm{E}_{\mathrm{C}}\left(\beta_{i k t}\right) \mathbf{F}_{\mathbf{k t}}+\mathrm{E}_{C}\left(\varepsilon_{i t}\right)
$$

Since $\mathrm{E}_{\mathrm{C}}\left(\mathbf{R}_{\mathrm{it}}\right)=\mathbf{R}_{\mathrm{mt}}$, and $\mathbf{R}_{\mathrm{mt}}$ and $\mathbf{F}_{\mathrm{kt}}$ are uncorrelated,

$$
\mathrm{E}_{\mathrm{C}}\left(\beta_{i t}\right)=1
$$

This is consistent with the intuition that beta of the whole market is always one.

In estimating the above model, we assume that market betas of each stock are constant over a fixed interval, e.g. 60 months, but are variable under a longer time period. In addition, we assume that the expectation of time-varying beta of each stock is one.

Imagine we have $J$ observations (over the above mentioned fixed interval) to estimate $\beta_{i t}$ under OLS framework. Then the OLS estimator $b_{i t} \sim \mathrm{N}\left(\beta_{i t}, \sigma_{i, t}^{2}\left(\operatorname{Diag}^{m}\left(\left(\mathbf{F}_{\mathbf{t}} \mathbf{F}_{\mathbf{t}}\right)^{-1}\right)\right)\right)$, and

$$
\left(\mathrm{b}_{\mathrm{it}}-1\right) \sim \mathrm{N}\left(\left(\beta_{i t}-1\right), \sigma_{i t}^{2}\left(\operatorname{Diag}^{m}\left(\left(\mathbf{F}_{\mathbf{t}} \mathbf{F}_{\mathbf{t}}\right)^{-1}\right)\right)\right)
$$

where $\operatorname{Diag}^{m}\left(\left(\mathbf{F}_{\mathbf{t}}{ }^{\prime} \mathbf{F}_{\mathbf{t}}\right)^{-1}\right)$ is the diagonal term of the $\left(\mathbf{F}_{\mathbf{t}}{ }^{\prime} \mathbf{F}_{\mathbf{t}}\right)^{-1}$ for the market beta, $\sigma_{i t}^{2}$ is the disturbance variance. $\sigma_{i t}^{2}$ can be estimated with $\left(\sum_{j=1}^{\mathrm{J}} e_{i, j}^{2} /(\mathrm{J}-\mathrm{K}-1)\right)$, where $e_{i, j}$ is the residual term of the regression. ${ }^{15}$

\footnotetext{
${ }^{15}$ For the robust M-estimation, the estimated coefficients are asymptotically normal, i.e., $b_{i t} \stackrel{a}{\mathrm{~N}}\left(\beta_{i t}, \sigma_{i t}^{2}\left(\operatorname{Diag}^{m}\left(\left(\mathbf{F}_{\mathbf{t}} \mathbf{F}_{\mathbf{t}}\right)^{-1}\right)\right)\right)$, where $\sigma_{i, t}$ can be estimated with the larger of robust estimate of sigma and a weighted average of OLS estimate of sigma and robust estimate of sigma. Here we only show the case of OLS estimation, and the conclusion applies to the robust M-estimation asymptotically.
} 


\section{Appendix I (continued)}

Assume the expectation of the beta of each stock is one, then

$$
\left(\mathrm{b}_{\mathrm{it}}-1\right) \sim \mathrm{N}\left(0, \sigma_{i t}^{2}\left(\operatorname{Diag}^{m}\left(\left(\mathbf{F}_{\mathbf{t}} \mathbf{F}_{\mathbf{t}}\right)^{-1}\right)\right)\right)
$$

At time $t$, let $X=\left[\begin{array}{c}\left(\mathrm{b}_{1 \mathrm{t}}-1\right) \\ \ldots \\ \left(\mathrm{b}_{\mathrm{Nt}}-1\right)\end{array}\right] \sim \mathrm{N}(0, \boldsymbol{\Phi})$, then $\boldsymbol{\Phi}$, the covariance matrix, is positive-definite, with diagonal terms $\sigma_{i t}^{2}\left(\operatorname{Diag}^{m}\left(\left(\mathbf{F}_{\mathbf{t}} \mathbf{F}_{\mathbf{t}}\right)^{-1}\right)\right) \quad\left(i=1, \ldots, \mathrm{N}_{\mathrm{t}}\right)$

Define $Y$ as a quadratic polynomial of $X:^{16}$

$$
Y=X^{\prime}\left(\mathbf{I} / \mathrm{N}_{t}\right) X
$$

where I is identity matrix.

Let $\mathrm{z}$ be the Cholesky matrix of $\boldsymbol{\Phi}$, and define $\mathrm{u}$ as a square matrix whose rows comprise orthonormal eigenvectors of $\left(\mathbf{z}^{\prime}\left(\mathbf{I} / \mathrm{N}_{\mathrm{t}}\right) \mathbf{z}\right)$. By construction, $\mathbf{u}$ is orthogonal.

Define the change of variables:

$$
Z=\mathbf{u z}^{-1} X
$$

Then $Z$ is multivariate normal with mean vector

$$
\mathrm{E}(Z)=\mathrm{E}\left(\mathbf{u z}^{-1} X\right)=\mathbf{u z}^{-1} \mathrm{E}(X)=0
$$

And covariance matrix

$$
\operatorname{Cov}(Z)=\left(\mathbf{u z}^{-1}\right) \boldsymbol{\Phi}\left(\mathbf{u z}^{-1}\right)^{\prime}=\left(\mathbf{u z} \mathbf{z}^{-1}\right) \mathbf{\Phi}\left(\mathbf{z}^{-1}\right)^{\prime} \mathbf{u}^{\prime}=\mathbf{u} \mathbf{I} \mathbf{u}=\mathbf{I}
$$

So $Z \sim \mathrm{N}_{N_{t}}(0, \mathbf{I})$.

Then $Y=X^{\prime}\left(\mathbf{I} / \mathrm{N}_{t}\right) X=\left(\mathbf{z u}^{-1} Z\right)^{\prime}\left(\mathbf{I} / \mathrm{N}_{\mathrm{t}}\right)\left(\mathbf{z u}^{-1} Z\right)=Z^{\prime}\left(\mathbf{u z}\left(\mathbf{I} / \mathrm{N}_{\mathrm{t}}\right) \mathbf{z u} \mathbf{u}^{\prime}\right) Z=\left(Z^{\prime} \mathbf{c} Z\right) / \mathrm{N}_{\mathrm{t}}$

where $\mathbf{c}=\mathbf{z}^{\prime} \mathbf{z}$.

Since we define $\mathbf{u}$ as a matrix whose rows comprise orthonormal eigenvectors of $\mathbf{z}^{\prime}\left(\mathbf{I} / \mathbf{N}_{t}\right) \mathbf{z}$, by the Spectral Theorem of linear algebra, the matrix $\mathbf{u z}\left(\mathbf{I} / \mathrm{N}_{\mathrm{t}}\right) \mathbf{z u}$ ' is diagonal with diagonal elements equal to the eigenvalues of $\mathbf{z}^{\prime}\left(\mathbf{I} / \mathrm{N}_{\mathrm{t}}\right) \mathbf{z}$. Then, $Y$ depends on only diagonal terms of the form $c_{i, i} Z^{2}$, and can be written as:

$$
Y=\left(\sum_{i=1}^{\mathrm{N}_{\mathrm{t}}} c_{i, i} Z^{2}\right) / \mathrm{N}_{\mathrm{t}}
$$

\footnotetext{
${ }^{16}$ This part is a special case of the quadratic polynomials of joint-normal random vectors, which is discussed in Holton (2003). 


\section{Appendix I (continued)}

When $\mathrm{N}_{\mathrm{t}}$ is large, we have simulated the distribution of variable $Y$ with different combinations of eigenvalues of $\mathbf{z}^{\prime}\left(\mathbf{I} / \mathrm{N}_{\mathrm{t}}\right) \mathbf{z}$, finding that only in one case, when one of the eigenvalues is much larger than the others, $Y$ deviates from normal distribution with large skewness and kurtosis; otherwise, $Y$ is very close to normal distribution.

We then go through the real data in various markets for the eigenvalues of matrix $\mathbf{z}^{\prime}\left(\mathbf{I} / \mathrm{N}_{t}\right) \mathbf{z}$, and observe that the exceptional case of one large eigenvalue rarely happens in reality. So we suggest approximating $Y$ with normal distribution.

Since $\mathbf{z z}^{\prime}=\Phi$, the sum of eigenvalues of $\mathbf{z}^{\prime} \mathbf{z}$ equal to the sum of diagonal terms of $\Phi$, i.e., $\sum_{i=1}^{N_{t}}\left[\sigma_{i t}^{2}\left(\operatorname{Diag}^{m}\left(\left(\mathbf{F}_{\mathbf{t}}{ }^{\prime} \mathbf{F}_{\mathbf{t}}\right)^{-1}\right)\right)\right]$.

So the expectation of $Y$ is $\mathrm{E}(Y)=\mathrm{E}\left(\frac{\sum_{i=1}^{\mathrm{N}_{\mathrm{t}}} c_{i, i} Z^{2}}{\mathrm{~N}_{\mathrm{t}}}\right)=\frac{\sum_{i=1}^{\mathrm{N}_{\mathrm{t}}}\left[\sigma_{i t}^{2}\left(\operatorname{Diag}^{m}\left(\left(\mathbf{F}_{\mathbf{t}} \mathbf{F}_{\mathbf{t}}\right)^{-1}\right)\right)\right]}{\mathrm{N}_{\mathrm{t}}}$

Define the variance of $Y$ as $\operatorname{Var}(Y)$,

$$
\operatorname{Var}(Y)=\operatorname{Var}\left(\frac{\sum_{i=1}^{\mathrm{N}_{\mathrm{t}}} c_{i i} Z^{2}}{\mathrm{~N}_{\mathrm{t}}}\right)<\frac{2 *\left\{\sum_{i=1}^{\mathrm{N}_{\mathrm{t}}}\left[\sigma_{i t}^{2}\left(\operatorname{Diag}^{m}\left(\left(\mathbf{F}_{\mathbf{t}} \mathbf{F}_{\mathbf{t}}\right)^{-1}\right)\right)\right]\right\}^{2}}{\mathrm{~N}_{\mathrm{t}}^{2}}=2[\mathrm{E}(Y)]^{2}
$$

We check the relative magnitude of $\mathrm{E}(Y)$ and $\operatorname{Var}(Y)$, and observe that, in all the markets, $\operatorname{Var}(Y)<<\mathrm{E}(Y)$. Thus, we suggest approximating the distribution of $\log (Y)$ by a normal distribution with mean $m$ and variance $s^{2}$, where

$$
\mathrm{E}(\log (Y)) \cong \log \left(\mathrm{E}(Y)=\log \left(\frac{\sum_{i=1}^{\mathrm{N}_{\mathrm{t}}}\left[\sigma_{i t}^{2}\left(\operatorname{Diag}^{m}\left(\left(\mathbf{F}_{\mathbf{t}} \mathbf{F}_{\mathbf{t}}\right)^{-1}\right)\right)\right]}{\mathrm{N}_{\mathrm{t}}}\right)\right.
$$




\section{Appendix II}

The Kalman Filter

In general, a state space model can be defined with two equations:

$$
\begin{aligned}
& \mathbf{Y}_{\mathbf{t}}=\mathbf{c}+S \mathbf{X}_{\mathbf{t}}+e_{t} \\
& \mathbf{X}_{\mathbf{t}}=\mathbf{d}+H \mathbf{X}_{\mathbf{t}-\mathbf{1}}+z_{t}
\end{aligned}
$$

where $\mathbf{X}_{\mathbf{t}}$ is the hidden vector at time $t, \mathbf{Y}_{\mathbf{t}}$ is the observation vector at time $t, c$ and $d$ are vectors with constants, $e$ is the measurement error, and $z$ is the state error. $e$ and $z$ are both multivariate normally distributed, with mean zero and covariance matrices of $\mathbf{R}$ and $\mathbf{Q}$, respectively.

The Kalman filter is an algorithm to perform filtering on this state-space model. The goal is to minimize the difference between the observation $Y_{t}$ and the prediction based on the previous observations $Y_{t \mid t}=P\left[Y_{t} \mid Y_{1}, \ldots, Y_{t-1}\right]$. This can be accomplished by recursive maximum likelihood estimation. The estimation of the state equation by the Kalman filter algorithm also offers a smoothed time series, by performing fixed-interval smoothing, i.e., computing $Y_{t \mid t}=P\left[Y_{t} \mid Y_{1}, \ldots Y_{T-1}\right]$, for $t \leq T$.

The Kalman filter can be regarded as an online estimation procedure, which is used to estimate the parameters online when new observations are coming in only after they have been estimated. In contrast, the Kalman smoother can be thought of as an offline procedure, which is only used when the total series have been observed. The Kalman filter results in approximations of the maximum likelihood estimates, while the smoother results in exact maximum likelihood estimates. 


\section{Appendix III}

Comparison of Ordinary Least Square and Robust Regression

Table A1 shows the objective functions and weight functions for the ordinary least squares estimator and the Huber estimator. Both of them increase without bound as the residual departs from 0 , but the Huber objective function increases more slowly. Least squares assigns equal weight to each observation; the weights of the Huber estimator decline for $|e|>k$, where e is the residual term, and $\mathrm{k}$ is called a tuning constant for the Huber estimator.

A smaller $k$ provides more resistance to outliers, but at the expense of lower efficiency when the errors are normally distributed. In general, $k=1.345 \sigma$ for the Huber (where $\sigma$ is the conventional standard deviation), producing 95\% efficiency when the errors are normal, and still offering protection against outliers.

\section{Table A1}

Objective function and weight function of least squares and Huber estimations

\begin{tabular}{lcc}
\hline \multicolumn{1}{c}{ Method } & Objective Function $(\boldsymbol{\rho})$ & Weight Function $\left(w_{i}\right)$ \\
\hline Ordinary Least Squares & $e^{2}$ & 1 \\
Huber Robust & $\begin{cases}e^{2} / 2 & (\text { when }|e| \leq k) \\
k|e|-k^{2} / 2 & (\text { when }|e|>k)\end{cases}$ & $\left\{\begin{array}{cc}1 & (\text { when }|e| \leq k) \\
k /|e| & (\text { when }|e|>k)\end{array}\right.$ \\
\hline
\end{tabular}




\section{References}

Aiken, A. (2005), "The existence and causes of investor sentiment in emerging markets," Working Paper.

Bikhchandani, S. and S. Sharma (2001), "Herd behavior in financial markets," IMF Staff Papers, 47, pp. 279-310.

Blume, M. (1971), “On the assessment of risk,” Journal of Finance, 26, pp. 1-10.

Braun, P., D. Nelson, and A. Sunier (1995), “Good news, bad news, volatility and betas," Journal of Finance, 50, pp. 1575-1603.

Bry, G. and C. Boschan (1971), "Cyclical analysis of time series: Selected procedures and computer programs," NBER.

Chang, E., J. Cheng, and A. Khorana (2000), "An examination of herd behavior in equity markets: An international perspective," Journal of Banking and Finance, 24, pp. 1651-1679.

Choe, H., B. Kho, and R. Stulz (1999), "Do foreign investors destabilize financial markets? The Korean experience in 1997," Journal of Financial Economics, 54, pp. 227-264.

Christie, W. and R. Huang (1995), "Following the pied piper: Do individual returns herd around the market?,” Financial Analysts Journal, July-August, pp. 31-37.

DeBondt, W and R. Thaler (1985), "Does the stock market overreact," Journal of Finance, 40, pp. 793-805.

Devenow, A. and I. Welch (1996), "Rational herding in financial economics," European Economic Review, 40, pp. 603-615.

Fabozzi, F. and J. Francis (1977), "Stability tests for alphas and betas over bull and bear market conditions,” Journal of Finance, 32, pp. 1093-1099.

Faff, R. and R. Brooks (1998), "Time varying beta risk for Australian industry portfolios: An exploratory analysis," Journal of Business Finance and Accounting, 25, pp. 721-745.

Fama, E. and K. French (1993), "Common risk factors in the returns of stocks and bonds," Journal of Financial Economics, 33, pp. 3-56.

Fama, E. and K. French (1996), "Multifactor explanations of asset pricing anomalies," Journal of Finance, 51, pp. 55-84.

Fama, E. and J. Macbeth (1973), "Risk, return and equilibrium: Empirical tests," Journal of Political Economy, 81, pp. 607-636.

Fernandez, P. (2004), “Are calculated beta worth for anything?," IESE Business School Working Paper.

Ferson, W. and C. Harvey (1999), "Conditioning variables and the cross section of stock returns," Journal of Finance, 54, pp. 1325-1360.

Grinblatt, M., S. Titman, and R. Wermers (1995), "Momentum investment strategies, portfolio performance, and herding: A study of mutual fund behavior," American Economic Review, 85, pp. 1088-1105. 
Groenewold, N. and P. Fraser (2000), "Forecasting beta: How well does the 'five-year rule of thumb' do?,” Journal of Business Finance and Accounting, 27, pp. 953-982.

Hampel, F., E. Ronchetti, P. Rousseeuw, and W. Stahel (1986), "Robust statistics: The approach based on influence functions," John Wiley \& Sons.

Hirshliefer, D. (2001), "Investor psychology and asset pricing," Journal of Finance, 56, pp. 15331597.

Holton, G. (2003), "Value-at-risk: theory and practice," Academic Press.

Huang, S. and M. Salmon (2004), "Market stress and herding," Journal of Empirical Finance, 11 , pp. 585-616.

Jegadeesh, N. and S. Titman (1993), "Returns to buying winners and selling losers: Implications for stock market efficiency,” Journal of Finance, 48, pp. 65-91.

Jirasakuldech, B., D. Dudney, and T. Zorn (2004), "The P/E multiple, market efficiency and bubbles," University of Nebraska-Lincoln Working Paper.

King, R. and C. Plosser (1989), "Real business cycles and the test of the Adelmans," NBER Working Paper 3160.

Komulainen, T. (2001), "Currency crisis in emerging markets: Capital flows and herding behavior,” Bank of Finland, Institute for Economies in Transition, Discussion Paper 10.

Lakonishok, J, A. Shleifer, and R. Vishny (1992), “The impact of institutional trading on stock prices," Journal of Financial Economics, 32, pp. 23-43.

Lintner, J. (1965), "The valuation of risk assets and the selection of risky investments in security portfolios and capital budgets," Review of Economics and Statistics, 47, pp. 13-37.

Martin, R. and T. Simin (1997), “Robust beta mining," IEEE Proceedings of KDD’97 (Workship on Issues in the Integration of Data Mining and Data Visualization).

Shanken, J. (1987), "Multivariate proxies and asset pricing relations," Journal of Financial Economics, 18, pp. 91-110.

Sharpe, W. (1964), "Capital asset prices: A theory of market equilibrium under conditions of risk," Journal of Finance, 19, pp. 425-442.

Stromberg, A. (2004), "Why write statistical software? The case of robust statistical methods," Journal of Statistical Software, 10, pp. 1-8.

Wermers, R. (1995), "Herding, trade reversals, and cascading by institutional investors," University of Colorado Working Paper. 